This item was submitted to Loughborough's Research Repository by the author.

Items in Figshare are protected by copyright, with all rights reserved, unless otherwise indicated.

\title{
Multi-impurity adsorption model for modeling crystal purity and shape evolution during crystallization processes in impure media
}

\section{PLEASE CITE THE PUBLISHED VERSION}

http://dx.doi.org/10.1021/acs.cgd.5b00320

\section{PUBLISHER}

(C) American Chemical Society (ACS)

\section{VERSION}

AM (Accepted Manuscript)

\section{PUBLISHER STATEMENT}

This work is made available according to the conditions of the Creative Commons Attribution-NonCommercialNoDerivatives 4.0 International (CC BY-NC-ND 4.0) licence. Full details of this licence are available at: https://creativecommons.org/licenses/by-nc-nd/4.0/

\section{LICENCE}

CC BY-NC-ND 4.0

\section{REPOSITORY RECORD}

Borsos, Akos, Aniruddha Majumder, and Zoltan Nagy. 2017. "Multi-impurity Adsorption Model for Modeling Crystal Purity and Shape Evolution During Crystallization Processes in Impure Media”. figshare. https://hdl.handle.net/2134/26038. 


\section{Multi-impurity adsorption model for modeling}

\section{crystal purity and shape evolution during}

\section{crystallization processes in impure media}

Akos Borsos ${ }^{a}$, Aniruddha Majumder ${ }^{a, \dagger}$, Zoltan K. Nagy ${ }^{a, b, *}$

${ }^{a}$ Chemical Engineering Department, Loughborough University, Loughborough, LE11 3TU, UK

${ }^{b}$ School of Chemical Engineering, Purdue University, West Lafayette, IN 47907-2100, USA

${ }^{\dagger}$ Present address: School of Engineering, University of Aberdeen, Aberdeen, AB24 3FX, UK

*Corresponding author: zknagy@purdue.edu

KEYWORDS: Real-time image analysis, Impurity modeling, Crystal purity, Multi-component and multi-site adsorption, Morphological population balance model, Crystal growth modifier

ABSTRACT: The impurity effect on the crystal properties, such as particle size and shape distribution is significant, having significant impact on the downstream processes as well as on the product effectiveness. Currently very few studies exist that provide a quantitative model to describe crystal purity resulting from crystallization processes in impure media and none to take 
into account the simultaneous effect of multiple impurities. Hence, the understanding of the effect of multiple impurities on crystallization process is important in order to obtain the desired product properties. Batch crystallization of potassium dihydrogen phosphate (KDP) from aqueous solution in the presence of impurities was investigated experimentally by using online Particle Vision and Measurement (PVM) tool with real-time image analysis. A mathematical model to describe crystal purity and aspect ratio is proposed based on a morphological population balance equation including primary nucleation, growth of characteristic faces and multi-site, competitive adsorption of impurities. The model parameters were identified and validated using crystallization experiments in mixtures of two impurities with variable composition. The developed and validated model can be an efficient tool for the investigation of crystallization processes in impure media with multiple impurities. The model can also serve as an effective tool for process and product design or optimization.

\section{Introduction}

Crystallization is a key separation process used by many process industries, including food, pharmaceutical and fine chemicals. The key crystalline product properties that are controlled by the crystallization process are purity, polymorphic form, size and shape distributions, which all have significant effect on the efficiency of downstream operations and on the product effectiveness, such as bioavailability or tablet stability. Although the key objective of crystallization is purification, very few contributions exist that provide quantitative models that are able to describe the effect of impurities in solution on the purity of the product crystals together with their influence on size and shape. Additionally, quantitative description of the 
interplay between crystal purity and size and shape distribution is important to exploit the potential that growth modifiers may offer for shape control ${ }^{1-4}$.

Controlling crystal shape distribution can be achieved by using different operational procedures. It is possible by combining crystallization with other unit operations such as milling as post process treatment ${ }^{5}$. Shape control is also possible by manipulating the operating parameters during crystallization. The control of supersaturation is the most common way to manipulate crystal shape ${ }^{6-8}$, although it provides a very narrow window for shape manipulation ${ }^{9}$. Induced crystal breakage can also be used for shape manipulation, typically for decreasing aspect ratio of needle shaped crystals. Breakage and attrition of the particles caused by stirring was studied experimentally as well as theoretically by numerous researchers ${ }^{10-12}$. The effect of impurities on the crystal shape is an area of increasing interest in crystallization with considerable amount of experimental work looking into shape changes and purity of the product $^{13-17}$. Several mathematical models including nucleation and growth kinetics for crystallization in the presence of impurities was proposed in the past ${ }^{18,19}$, however considering the effect of single impurity in the system. Rosenberg and Riveros developed a mathematical model and investigated the effects of impurity based on the heat of mixing terms, while Cabrera and Vermilyea, Davey and Sizemore et al. developed mathematical models based on adsorption theorems $\mathrm{s}^{20-23}$. Kubota and Mullin, Kubota and Kubota and co-workers developed a model, using Langmuir's adsorption isotherm ${ }^{24-26}$. This model was further improved and combined with population balance modelling and mass balance to describe the dynamic variation of crystal purity as well as shape distribution by Majumder and Nagy, in order to investigate and control the shape evolution of KDP crystals $^{27}$. 
The aforementioned models only consider the effect of a single impurity, although crystallization often occurs in impure media with multiple impurity species acting simultaneously. In other areas of chemical processes, such as chromatography, extended Langmuir adsorption models have been developed in order to describe multi-component adsorption mechanisms ${ }^{28,29}$. Furthermore, Lim et al. investigated competitive adsorption of enantiomers on dual-site adsorbent ${ }^{30}$, while different adsorption mechanisms were described and investigated by Gu et al. ${ }^{31}$. Recently a morphological population balance model for describing the competitive adsorption of impurities was developed ${ }^{32}$. In this work these models are extended and combined with population balance model and mass balance equations to provide a novel multi-impurity adsorption model (MIAM) for the simultaneous modelling of the effect of multiple impurities in the crystallization slurry with different possible adsorption mechanisms on the crystal purity and shape and size distribution of solid product.

Effective monitoring techniques are required in order to attain proper shape control of crystallization as well as to determine kinetic parameters and product properties. Most of these techniques and sensors for particle shape characterization are imaging and video microscopy tools coupled with image analysis. An early work of image analysis based process monitoring and optical imaging was developed and applied by Patience et al. ${ }^{33}$. There are numerous companies that provide in situ imaging sensors (e.g., DuPont, USA; Perdix, The Netherlands; Mettler-Toledo, Switzerland) as well as flow-through cell imaging devices (Malvern, U.K.; Sympatec, U.K.) $)^{3,8,18,34}$. Low-cost, endoscope based systems were also integrated into process monitoring system ${ }^{35}$. Different image analysis strategies have been developed in order to obtain information about the crystallization process, including the detection of nucleation or metastable zone width, particle size and crystal polymorphs ${ }^{8,34,36-40}$. The image analysis based process 
monitoring can provide necessary data for model development, validation and process control $^{3,41,42}$. Population balance modeling is widely used in order to describe the evolution of crystal properties such as size and shape distribution ${ }^{43,44}$. Multidimensional population balance models are suitable for investigation and simulation of crystal morphology when the shape of the particles is described by the sizes of the characteristic crystal faces ${ }^{9,45-53,78}$.

The aim of the present work is to investigate crystallization processes in impure media in the presence of multiple impurities, with impact on the crystal shape via growth kinetics. The broad impact off the crystal growth modifiers (impurities) on the growth kinetics is observed in real time by using in situ video imaging probe and real-time image analysis. A morphological population balance model is developed, which incorporates a multi-site, competitive adsorption mechanisms of the impurities on the crystal faces. The kinetic parameters of primary nucleation, growth and impurity adsorption for a model system of potassium dihydrogen phosphate (KDP) crystallization in water in the presence of two impurities, were estimated and validated with experimental results. Using a model-based sensitivity analysis, it was demonstrated that the model can be used to describe the dynamic evolution of crystal properties, such as size and aspect ratio during crystallization for different impurity profiles in the system.

\section{Materials and methods}

\subsection{Materials and experimental setup}

Pure potassium dihydrogen phoshpate (KDP) provided by Fisher Scientific (purity: >99.5\%), aluminium sulphate (CGM1) from Sigma-Aldrich (purity: >98\%), sodium hexametaphosphate (CGM2) from Fisher Scientific (purity: >97\%) and deionised water of laboratory grade were 
used in all experiments. The physical experiments were performed in a $1000 \mathrm{ml}$ jacketed glass vessel. The temperature was measured by a PT100 thermocouple, recorded and controlled by Crystallization Process Informatics System (CryPRINS) software via a Huber Ministat 230 thermostat. The process was monitored in situ using a Lasentec Particle Vision and Measurement V819 (PVM) probe which was set up to capture 6 images in a second. Images were simultaneously acquired and analyzed by Lasentec PVM On-Line Image Acquisition and the Lasentec PVM Stat Acquisition software.

Initially, the crystallizer was heated up and temperature was held at $50{ }^{\circ} \mathrm{C}$ until all solids dissolved. Subsequently the temperature was lowered to $45{ }^{\circ} \mathrm{C}$, which is slightly above the equilibrium temperature at the solute concentration used. Finally, linear cooling rate was applied from $45{ }^{\circ} \mathrm{C}$ to $20^{\circ} \mathrm{C}$ in $180 \mathrm{~min}$. The same temperature profile was used in each experiment.

Table 1 shows the amounts of substances used in all experiments. The first three experiments were used for parameter estimation of the primary nucleation and growth kinetics, while the other six were used for validation of the model predictions.

Table 1. Materials with amounts used in each experiment.

\begin{tabular}{crrrr}
\hline No. & H2O [g] & KDP [g] & CGM1 [ppm] & CGM2 [ppm] \\
\hline Exp1 & 400 & 150 & 0 & 0 \\
Exp2 & 400 & 150 & 12.5 & 0 \\
Exp3 & 400 & 150 & 0 & 5 \\
Exp4 & 400 & 150 & 17.5 & 0 \\
Exp5 & 400 & 150 & 12.5 & 7.5 \\
Exp6 & 300 & 112.5 & 11.5 & 0 \\
Exp7 & 300 & 112.5 & 11.2 & 5.4 \\
Exp8 & 300 & 112.5 & 12.6 & 11.8 \\
Exp9 & 300 & 112.5 & 17.2 & 11.7 \\
\hline
\end{tabular}


The effect of growth modifiers on the shape is closely linked to the molecular arrangement in the crystal lattice. Often different crystal faces exhibit different charges hence impurities with positive or negative charges will adsorb preferentially on different faces of the crystal ${ }^{16,24,27,54-}$ ${ }^{57,75-78}$. In the case of the current work, divalent and trivalent metal ions preferably adsorb on the $\{100\}$ face of KDP crystal, which leads to decreased growth rate of the corresponding characteristic length. While anionic growth modifiers preferentially adsorb on the $\{101\}$ face resulting growth rate inhibition for the corresponding characteristic length. Therefore the presence of CGM1 in the crystallization media results in increased aspect ratio (AR) of the crystal, while CGM2 has the opposite effect of decreasing the aspect ratio.

\subsection{Observation, image analysis}

Generally, imaging sensors such as PVM generates images or image sequences during the process, which can be used to obtain meaningful information about crystal properties. The image analysis techniques applied in the crystallization literature, can be divided in two main classes ${ }^{18}$. The first category includes strategies which are based on using texture analysis to detect changes in the image descriptors ${ }^{58-61}$. The second type of techniques is based on image segmentation and detection. This method detects the boundary of the crystals using blob analysis. Numerous studies use the blob analysis technique in order to obtain information about particle number and particle size or shape distribution ${ }^{4,39,40,62,63}$. The online image analysis methodology applied here is similar to the work of Zhou et al. ${ }^{62}$, and contains the following steps based on the generic blob analysis strategy: (1) imaging/selection, (2) image enhancement, (3) edge detection, (4) morphology operation, (5) calculation of the rate of changes of the edges. 
Many of these studies have discussed the difficulties of the image analysis, which cause errors and/or noise in the detected property; and it is notable that the monitoring conditions such as imaging frequency, particle number density, particle size ranges can have significant impact on the quality of the detection and the accuracy of the results. Several different strategies were developed to decrease measurement error, for example due to particle overlapping, or orientation of the crystal and distance from probe ${ }^{61-65}$. Design of experiments also helps improving the accuracy of the parameter estimation. Experiments are often carried out in order to avoid multikinetic effects, such as nucleation, growth and/or additional events such as fragmentation or agglomeration. Hence, seeding and constrained supersaturation (e.g. achieved by supersaturation feedback control) are often used strategies ${ }^{80,81,82,83}$ to provide a framework of sequential parameter identification, using subset of experiments that trigger certain mechanisms or subsets of mechanisms For example seeded experiments with controlled supersaturation are commonly used to generate data that can decouple the estimation of growth kinetics from nucleation. However the experiments presented in this paper all used in situ seed generation to attempt to minimize uncertainties that may arise from variations in seed quality. Decoupled experiments were used instead to estimate the effects of each impurity on the growth kinetics independently. Additionally, since the concentrations of additives in the solution have a direct and much stronger effect on the crystal aspect ratio than on crystal purity (additives incorporate in the crystal in very low concentrations), the model parameters related to the impurity adsorption were estimated inferentially from the AR. Measuring the low concentration of impurities in the crystals can be difficult and subject to errors depending on sampling, filtration and washing procedures, hence using the more sensitive crystal property (AR) in the parameter estimation can yield better model parameters than using off-line crystal purity measurements. 
Although PVM probes are extensively used for qualitative in situ visualization of crystals during crystallization, it is very seldom used for quantitative image analysis (IA). This work demonstrates that the PVM probe connected to the image analysis software is a suitable tool for automated in-situ and real-time measurement of the crystal size and shape distribution by using blob analysis. Fig. 1a presents a sample raw picture with crystals captured by the PVM probe, whereas Fig. 1b shows the crystal with detected box representing the minimum and maximum Ferret sizes of crystals after enhancement as shown in the real-time on-line image acquisition software. The images were simultaneously analyzed and data of shape/aspect ratio distribution was recorded by the Lasentec PVM Stat Acquisition software. Images were acquired and individually analyzed with a frequency of 10 images per second and the results averaged with a frequency of 20 seconds. This frequency provided particle properties averaged from about 200 images, which was found to provide representative values. Fig. 2 shows an example of aspect ratio distribution during the process generated based on the information provided by the tool. The measurements provide real-time monitoring of the crystal shape changes in time. The spread of the aspect ratio distribution at the end of the process shows that the aspect ratios of the crystals are non-uniform. The real-time measurement of the AR distribution provides the opportunity to fit growth kinetics required for 2D morphological population balance based modeling. 

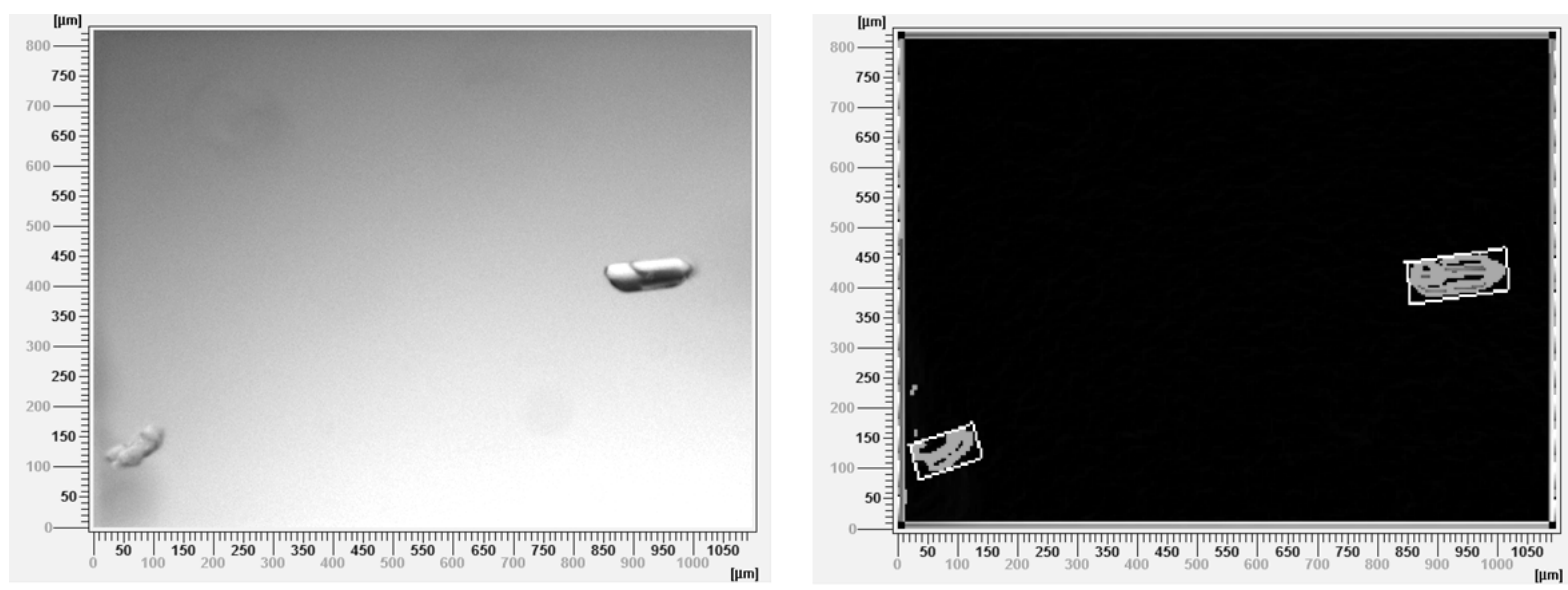

Figure 1 (a) Raw PVM image captured and (b) treated image in the on-line image acquisition software using blob analysis. ${ }^{32}$
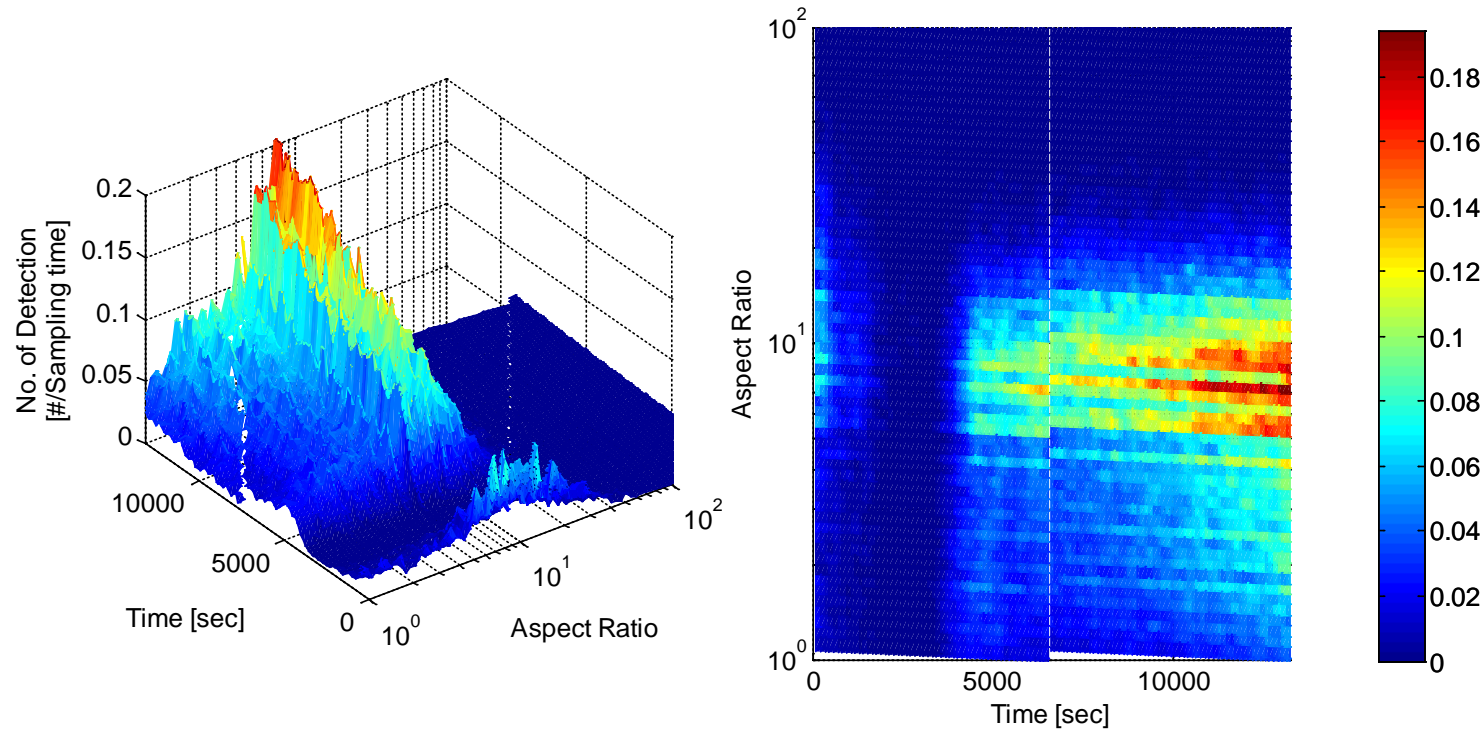

Figure 2. Evolution of the aspect ratio distribution during a crystallization process, measured and computed in real-time using the PVM probe with on-line image analysis. 


\section{Multi-dimensional PBM with multi-impurity adsorption model (MIAM) for crystallization processes}

There are considerable numbers of papers reporting on investigations of the effects of adsorption mechanism of crystal growth modifiers on the growth kinetics during crystallization. Despite the fact that most industrial crystallization processes occur in impure media where multiple impurities can have simultaneous effect on the crystallization process, in general all published literature focuses on the growth mechanisms influenced by a single impurity at a time ${ }^{21-23,66}$. Kubota and Mullin and Kubota et al. developed a growth kinetic model based on the Langmuir adsorption isotherms, considering only single CGM, which was used for example for the modeling of shape evolution of potassium dihydrogen phosphate (KDP) crystals in the presence of different type of impurities that selectively influence the growth of a particular crystal face $\mathrm{e}^{24-26}$.

Multi-component adsorption models have been used in the generic adsorption literature. Ruthven and $\mathrm{Gu}$ et al. provided on overview of the theories and models of adsorption ${ }^{28,31}$. Extended Langmuir adsorption models were developed by Rabe et al. for protein adsorption on solid surfaces ${ }^{29}$, whereas Lim et al. proposed a competitive adsorption model of enantiomers on dual site adsorbent ${ }^{30}$. Sitprasert et al. investigated a similar competitive adsorption model on dual site adsorbent in heterogeneous carbonaceous porous media ${ }^{67}$. More recently the competitive adsorption of multi-component CGMs on the growth mechanism was studied for the first time by Ferreira et al. ${ }^{68}$.

In the present work, a multi-impurity adsorption model (MIAM) is developed based on a multi-component, multi-site, multi-facet adsorption mechanism. The key steps of this mechanisms are shown schematically in Fig. 3 where $k=k_{1}, k_{2}, \ldots, k_{n}$ is the different types of 
adsorption sites, $j=j_{1}, j_{2}, \ldots, j_{n}$ are the various crystal growth modifiers (impurities) and $i=i_{1}, i_{2}$, $\ldots, i_{n}$ is the different type of crystal facets present in the system. In the case of multi-site adsorption, CGM can adsorb on different types of sites. When the different CGMs can compete with each other for the same site, the mechanism is called as competitive adsorption. In the case of multi-facet adsorption, active sites with same adsorptive behavior are located on different faces; however properties of it such as the site density or the effectiveness of it can be different. Thus, multi-surface adsorption means CGM is suitable to connect to sites which can be found on different facets.

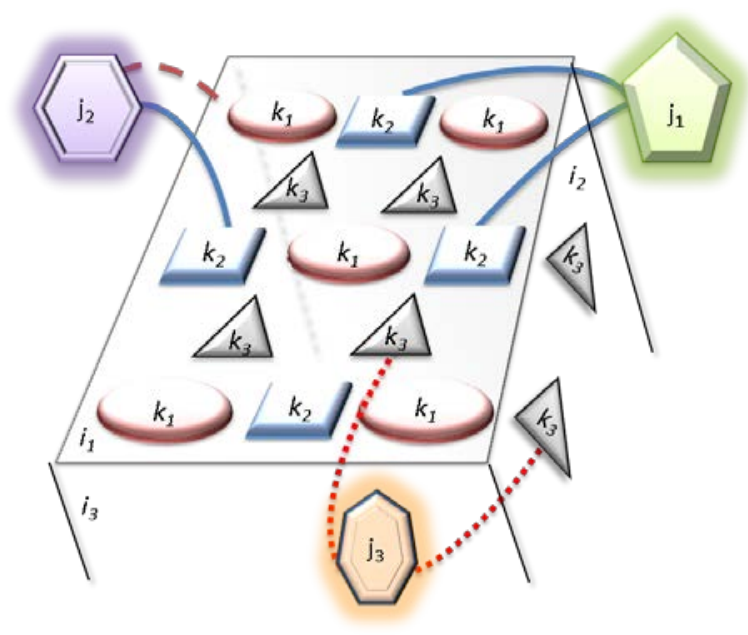

Figure 3. Schematic representation of the competitive multi-component multi-site and multi-face adsorption mechanism in the case of three components $(j=3)$ and three sites $(k=3)$ as well as three different types of faces $(i=3)$.

In accordance with the competitive, multi-site, multi-facet adsorption mechanism on a particular face $i$ of the crystal, the modified growth kinetics is described by the following equations: 


$$
G_{i}=k_{g, i}\left(\frac{c-c_{s a t}}{c_{s a t}}\right)^{g_{i}} p_{i m p, i}
$$

where $G_{i}$ is the growth rate of the $i^{\text {th }}$ characteristic crystal face, $c$ and $c_{\text {sat }}$ are the concentration of the solute in the solution and the saturation concentration, respectively. The terms $g_{i}, k_{g, i}$ are the growth exponent and kinetic coefficient. The power law type growth rate expression is used here arbitrarily as a generic empirical growth rate model. Growth mechanism, hence rate expressions/constants can change with supersaturation. However, the proposed MIAM model that modifies the nominal growth rate expression would be the same and is not directly dependent on the supersaturation. The model could be easily extended to use more mechanistic, supersaturation dependent nominal growth rate expressions. The term $p_{i m p, i}$ is the impurity coefficient on the $i^{\text {th }}$ face, which describes the combined effect of all CGMs on the crystal growth of the $i^{\text {th }}$ characteristic crystal face. The extended Langmuir adsorption isotherm model can be used to describe competitive adsorption on a multiple site adsorbent. According to this mechanism the $p_{\text {imp,i }}$ is described by the following equation:

$$
p_{i m p, i}=1-\sum_{j} \sum_{k}\left(\alpha_{i, k} \theta_{e q, i, j, k}\left[1-\exp \left(-\frac{\eta_{j}}{\tau_{i, j, k}}\right)\right]\right)
$$

where the right hand side of the equation represents the coverage on the $i^{\text {th }}$ crystal face by the $j^{\text {th }}$ CGM, when competitive adsorption is possible on multiple sites, with $\mathrm{k}$ being the number of different types of sites, $\eta_{j}$ is the time spent by a particle in the solution in the presence of impurities, and $\tau$ is the adsorption time constant. When the impurity is present in the solution from the beginning of the crystallization (e.g., originated from upstream processes) the contact time does not depend on the different additives, only on the ages of the particles. The $\alpha_{i, k}$ 
denotes the effectiveness factor of the adsorption on the $k^{\text {th }}$ site on $i^{\text {th }}$ characteristic face, similarly to the Kubota's model ${ }^{25}$.

$$
\alpha_{i, k}=\frac{\gamma_{i} a_{i}}{k_{B} T \sigma L_{i, k}}=\frac{\beta_{i, k}}{T \sigma}
$$

where $\gamma_{i}$ is the edge free energy on the $i^{\text {th }}$ crystal face per unit length, $a_{i}$ denotes the area per growth unit appearing on the crystal surface, $k_{B}$ is the Boltzmann constant $\left(1.3806 \mathrm{e}-23 \mathrm{~m}^{2} \mathrm{~kg} \mathrm{~s}^{-2}\right.$ $\left.\mathrm{K}^{-1}\right), T$ is temperature $(\mathrm{K}), \sigma$ denotes the relative supersaturation, $\sigma=\left(c-c_{\text {sat }}\right) / c_{\text {sat }}$ while $L_{i, k}$ is the average distance between $k^{\text {th }}$ type of sites.

The equilibrium coverage is which provides the connection between the concentration of the CGMs in the solution and the growth rate takes the form

$$
q_{e q, i, j, k}=\frac{K_{i, j, k} C_{C G M, j}}{1+\stackrel{\circ}{j}_{j} K_{i, j, k} C_{C G M, j}}
$$

The Langmuir constant, $K_{i, j, k}$, of the $j^{\text {th }}$ CGM on the $k^{\text {th }}$ active site on $i^{\text {th }}$ characteristic crystal face described by the adsorption and desorption rate coefficients. It may be expressed by ${ }^{66}$

$$
K_{i, j, k}=\frac{k_{a d s, i, j, k}}{k_{d e s, i, j, k}}=\frac{k_{a d s, 0, i, j, k}}{k_{d e s, 0, i, j, k}} \exp \left(\frac{\Delta G_{d e s, i, j, k}-\Delta G_{a d s, i, j, k}}{R T}\right)
$$

where $k_{a d s, i, j, k}$ and $k_{d e s, i, j, k}$ denote the adsorption and desorption rate coefficients, respectively; which can be expressed by the Arrhenius type forms including kinetic energies of adsorption and desorption. The $\Delta G_{a d s, i, j, k}, \Delta G_{d e s, i, j, k}$ are the free energies of the $j^{\text {th }}$ CGM adsorption and desorption on the $k^{\text {th }}$ sites at $i^{\text {th }}$ characteristic surface.

The adsorption time constant, $\tau$, is defined by Kubota and Mullin as ${ }^{24}$ : 


$$
\tau_{i, j, k}=\frac{1}{k_{a d s, i, j, k} c_{C G M_{i}}+k_{d e s, i, j, k}}
$$

Eq2 represents a non-equilibrium Langmuir adsorption model. However, high adsorption and/or desorption rates lead to fast approximation of the equilibrium. In this case, the exponential part of the equation can be neglected and equilibrium coverage may be considered ${ }^{24}$. The simplified growth kinetic model takes the form

$$
p_{i m p, i}=1-\sum_{j} \sum_{k}\left(\alpha_{i, k} \theta_{e q, i, j, k}\right)
$$

The population balance equation (PBE), in which two characteristic lengths $\mathbf{x}=\left\{x_{1}, x_{2}\right\}$ are considered to describe the evolution of the crystal shape distribution can be written as

$$
\frac{\partial}{\partial t} n(t, \mathbf{x})+\frac{\partial}{\partial x_{1}}\left[G_{1} n(t, \mathbf{x})\right]+\frac{\partial}{\partial x_{2}}\left[G_{2} n(t, \mathbf{x})\right]=B_{p} \delta\left(x_{1}-x_{1,0}\right) \delta\left(x_{2}-x_{2,0}\right)
$$

where $n(t, \mathbf{x})$ is the distribution function, $\delta\left(x-x_{0}\right)$ is the delta distribution which determines the appearance of the nuclei and $B_{p}$ is the primary nucleation rate defined as ${ }^{69,74}$

$$
B_{p}=k_{p, 0} \exp \left(-\frac{E_{p}}{R T}\right) \exp \left[-k_{e} \ln ^{-2}\left(\frac{c}{c_{s a t}}\right)\right]
$$

The $k_{p, 0}$ and $k_{e}$ are kinetic constants of primary nucleation. The initial and boundary conditions of the PBE take the form of

$$
\begin{aligned}
& n(0, \mathbf{x})=n_{0}(\mathbf{x}) \\
& G_{i} n(t, \mathbf{x})=0, \mathbf{x} \in \partial \Omega_{x}
\end{aligned}
$$

where $\partial \Omega_{\chi}$ is the boundary of the size space. The mass balance is also required for the solution of PBE. Concentration of solute is expressed as follows 


$$
\frac{d c(t)}{d t}=-\rho_{c} \frac{d \mu_{1,2}}{d t}
$$

where $\rho_{c}$ is the density of the solute crystals. The mass balance for the impurity concentration in the solution is ${ }^{27}$

$$
\frac{d c_{C G M, j}}{d t}=\frac{\chi_{c, j}}{1-\sum_{j} \chi_{c, j}} \frac{M_{C G M, j}}{M_{C}} \frac{d c}{d t}
$$

where $M_{\text {cGm }, j}$ and $M_{c}$ are the molecular weights of the impurities/CGMs and solute. The $\chi_{c, j}$ is the mole fraction of the $j^{\text {th }}$ CGM in the crystal phase, which can be written as the mole fraction of the $j^{\text {th }}$ CGM in the solution multiplied by its interfacial distribution coefficient, $K_{d, i, j}$. Thus the mole fraction can be given by

$$
\chi_{c, j}=\sum_{i} K_{d, i, j} \frac{c_{C G M, j}}{M_{C G M, j}}\left(\frac{c}{M_{c}}+\sum_{j} \frac{c_{C G M, j}}{M_{C G M, j}}\right)^{-1}
$$

The $c_{C G M, j}$ and $c$ are the concentrations of the $j^{\text {th }}$ CGM and solute, $M_{j}$ and $M_{c}$ are the molar weights of the $j^{\text {th }}$ CGM and the solute, while the distribution coefficient, $K_{d, i, j}$ is

$$
K_{d, i, j}=1-\left(1-K_{e, j}\right) \sqrt{\frac{G_{\min , i} k_{m, i, j}}{G_{i} k_{\min , i, j}}}
$$

In this equation, $K_{d, i, j}$ is thermodynamic distribution coefficient of the $j^{\text {th }}$ CGM, the $k_{m, j}$ and $k_{\min , j}$ are the mass transfer coefficients with crystal growth at the actual growth rate and at the $G_{\text {min,i }}$ which is the specific growth rate when impurity distribution does not occur ${ }^{70}$,

$$
k_{\min , i, j}=G_{\min , i}\left[1-\exp \left(-\frac{G_{\min , i}}{k_{m 0, j}}\right)\right]^{-1}
$$




$$
k_{m, i, j}=G_{i}\left[1-\exp \left(-\frac{G_{i}}{k_{m 0, j}}\right)\right]^{-1}
$$

where $k_{m 0, j}$ is mass transfer coefficients without crystal growth.

The solution of multidimensional PBE is computationally expensive. However, since only average properties are needed to calculate the mean aspect ratio (AR) of the crystals, the method of moments (MOM) can be used for efficient solution of the resulting multi-dimensional $\mathrm{PBE}^{71}$. The cross-moments in the two dimensional cases are calculated as the follows,

$$
\mu_{m, n}(t)=\int_{0}^{\infty} \int_{0}^{\infty} x_{1}^{m} x_{2}^{n} n(\mathbf{x}, t) d x_{1} d x_{2}, \mathrm{~m}, n=0,1,2 \ldots
$$

Using this moment definition the PBE is transformed in a set of ordinary differential equations. The general form of the moment equation system based on joint moments is

$$
\begin{aligned}
& \frac{d \mu_{0,0}}{d t}=B_{p} \\
& \frac{d \mu_{m, r}}{d t}=m G_{1} \mu_{m-1, r}+n G_{2} \mu_{m, r-1}, \quad m=1,2, \ldots \text { and } n=1,2, \ldots
\end{aligned}
$$

The closed set of the ordinary differential equation (ODE) system including moment equations and mass balances for the solute and impurities provides a detailed moment model of crystallization process in impure media. These moments determine parameters of the crystal population. The evolution of the particle number is calculated by the differential equation of the zeroth order joint moment, $\mu_{0,0}$. The $\mu_{1,2}$ moment is related to the crystal volume in a unit volume of the suspension. Moments are also suitable to determine indirectly the mean crystal sizes of the characteristic lengths, while the mean aspect ratio of the crystals can be calculated from the mean crystal sizes: 


$$
\begin{gathered}
\bar{x}_{1}=\frac{\mu_{0,1}}{\mu_{0,0}} \\
\bar{x}_{2}=\frac{\mu_{1,0}}{\mu_{0,0}} \\
\overline{A R}=\frac{\bar{x}_{1}}{\bar{x}_{2}}
\end{gathered}
$$

The model presented in this section that combines the multi-impurity adsorption model (MIAM) with multi-dimensional population balance equation and mass balances for solute and all impurities, provides a general modelling framework for crystallization in impure media. This model is the first one which is able to describe the effect of multiple impurities, simultaneously present in the crystallization media, on the crystal size and shape distribution as well as on the evolution of crystal lattice composition and purity.

\section{Model identification and validation and sensitivity study}

The crystallization of KDP (potassium dihydrogen phosphate) from solution was taken as the model system, for which multidimensional kinetic parameters are available in the

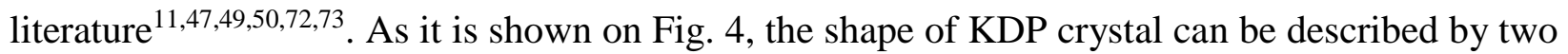
characteristic sizes $\left(x_{1}, x_{2}\right)$. The applied growth modifiers, which are used in the experimental and simulation studies have different impact on the KDP crystal. The CGM1 is aluminium sulphate dissociates into trivalent $\mathrm{Al}^{3+}$ metal ions can adsorb on the $\{100\}$ face. This adsorption mechanism leads to more needle like crystals. Sodium hexametaphosphate is considered as CGM2, which preferably adsorbs on the $\{101\}$ face. Hence, metaphosphate can result in opposite impact on the crystal shape (decrease the aspect ratio). 


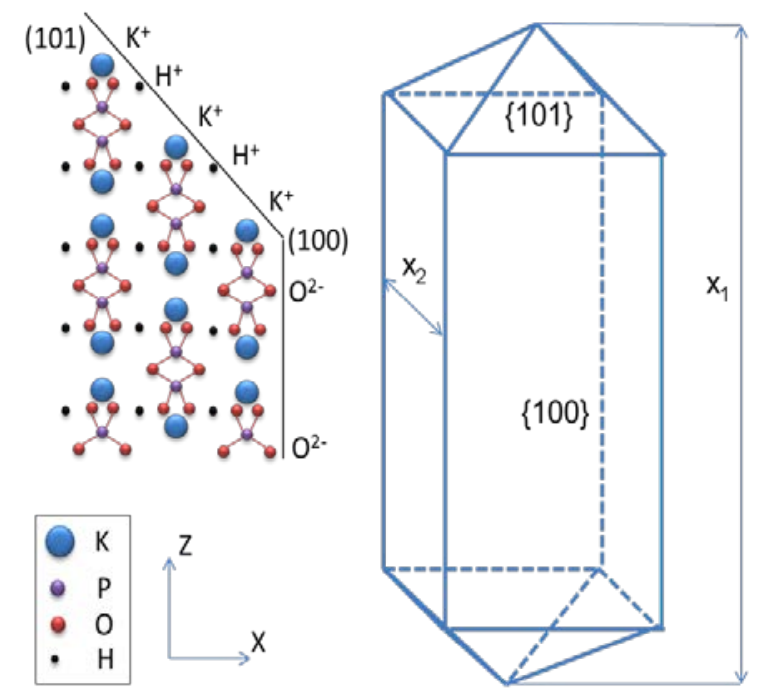

Figure 4. Molecular arrangement and morphology of the KDP crystal. ${ }^{54}$

In the case of the investigated processes, the kinetic model can be reduced by taking the following assumptions into account in accordance of the behavior of KDP crystals and the two CGMs considered:

1. Two impurities $(j=2)$ and two different types of active sites are considered $(k=2)$, which are located on two different crystal faces. On the $\{100\}$ face of the crystal, the effect of the negatively charged active sites is the dominant, which leads to preferential adsorption of CGM1. After experimental investigations, the effect of the positively charged active sites and adsorption of the CGM2 are neglected on this face.

2. The behavior of the $\{101\}$ face is opposite to the $\{100\}$ face. Thus, impact of the CGM1 is neglected here.

3. There is no interaction between the active sites (rare sites).

4. Impurity effect on the nucleation in this case is insignificant and neglected in the model.

5. Equilibrium adsorption model is considered 
After these assumptions, the growth kinetic models are reduced to the following forms:

$$
\begin{aligned}
& G_{1}=k_{g, 1}\left(\frac{c-c_{\text {sat }}}{c_{\text {sat }}}\right)^{g_{1}}\left\{1-\left(\alpha_{1,1} \frac{K_{1, C G M 1,1} C_{C G M 1,1}}{1+K_{1, C G M 1,1} C_{C G M 1,1}}\right)\right\} \\
& G_{2}=k_{g, 2}\left(\frac{c-c_{\text {sat }}}{c_{\text {sat }}}\right)^{g_{2}}\left\{1-\left(\alpha_{2,2} \frac{K_{2, C G M 2,2} C_{C G M 2,2}}{1+K_{2, C G M ~ 2,2} C_{C G M ~ 2,2}}\right)\right\}
\end{aligned}
$$

The power law growth expressions and/or growth rate parameters may be dependent on the supersaturation range the crystallization is operated. However, the maximum level supersaturation used in the experiments reported in this paper was moderate $\left(\sigma_{\max }<5 \%\right)$. It has been reported ${ }^{84}$ (Alexandru \& Antohe 2003) that for KDP crystals, at this level of supersaturation the growth mechanism for prismatic face $\{100\}$ does not change. Moreover it has been reported that growth of the pyramidal face $\{101\}$ at supersaturation below $5 \%$ is dominated by a dislocation mechanism ${ }^{85,86 .}$ These findings support the usage of the single growth kinetics model for the level of supersaturation used in these experiments; however the effect of the transient supersaturation on the growth rate expression can be included easily in the model by changing the equations or parameters of the growth model as a function of several levels of supersaturation.

The solubility [g/g solvent] of anhydrous KDP in water is given $b^{27}$,

$$
c_{\text {sat }}=0.2087-9.7629 e-5 \cdot T+9.3027 e-5 \cdot T^{2}
$$

where the temperature, $T$ is in ${ }^{\circ} \mathrm{C}$. Three of the nine experiments presented in Table 1 (Exp1, Exp2, Exp3), were used for parameter estimation. To minimize the difficulty associated with the simultaneous estimation of multiple, highly correlated kinetic parameters, the experiments were designed to decouple mechanisms and allow sequential parameter estimation. First, the kinetics 
of primary nucleation was investigated and fitted to experimental data by using the mathematical model in the case of KDP crystallization from pure aqueous solution (Exp1). The impurity parameters of CGM1 included in the growth rate equation are estimated by fitting data to Exp3. Finally, the parameters of the effect of CGM2 impurity on the growth kinetics are obtained by fitting the model to Exp2. The non-estimated kinetic parameters, which are used in the model were previously determined by Gunawan et al. ${ }^{26}$, Kubota et al. ${ }^{47}$, and Maeda et al. ${ }^{70}$. Parameter estimation was carried out in Matlab based on a standard nonlinear least square method. The estimation problem is defined as

$$
\begin{aligned}
& \min _{\Theta} \sum_{l}\left(y_{l}-\tilde{y}_{l}\right)^{2} \\
& \Theta_{B_{p}}=\left\lfloor k_{p, 0}, E_{p}, k_{e}\right\rfloor \\
& \Theta_{C G M 1}=\left[k_{C G M 1, a d s, 0}, k_{C G M 1, d e s, 0}, \beta_{1}, G_{\min , 1}, k_{C G M 1, m, o}, k_{C G M 1, e}, \Delta G_{C G M 1, a d s}, \Delta G_{C G M 1, \text { des }}\right] \\
& \Theta_{C G M 2}=\left[k_{C G M 2, a d s, 0}, k_{C G M 2, \text { des }, 0}, \beta_{2}, G_{\min , 2}, k_{C G M 2, m, o}, k_{C G M 2, e}, \Delta G_{C G M 2, \text { dds }}, \Delta G_{C G M 2, \text { des }}\right]
\end{aligned}
$$

where $y_{l}$ and $\tilde{y}_{l}$ are measured and calculated values of the mean aspect ratio in the lth sampling point in time. The $\Theta$ vectors are the various subsets of the vectors of the estimated model parameters. The results of the parameter estimation are presented in Table 2.

Table 2 Estimated values of the kinetic parameters.

\begin{tabular}{lllll}
\hline & $\Theta_{C G M 1}$ & $\Theta_{C G M 2}$ & & $\Theta_{B_{p}}$ \\
\hline $\mathrm{k}_{\mathrm{ads}, 0}$ & $27.3 \pm 13.8$ & $11.24 \pm 1.5$ & $\mathrm{k}_{\mathrm{p} 0}$ & $6.5 \pm 2.3$ \\
$\mathrm{k}_{\text {des }, 0}$ & $0.56562 \pm 1.7 \mathrm{e}-5$ & $0.49127 \pm 1.2 \mathrm{e}-5$ & $\mathrm{E}_{\mathrm{p}}$ & $2814.5 \pm 1.02 \mathrm{e} 3$ \\
$\beta$ & $4.6 \pm 1.44$ & $5.15 \pm 0.49$ & $\mathrm{k}_{\mathrm{e}}$ & $1.576 \mathrm{e}-3 \pm 2.8 \mathrm{e}-6$ \\
\hline
\end{tabular}




\begin{tabular}{lll}
\hline $\mathrm{G}_{\min , \mathrm{i}}$ & $4.5 \mathrm{e}-4 \pm 0.13$ & $246.952 \pm 2.8 \mathrm{e}-6$ \\
$\mathrm{k}_{\mathrm{m}, \mathrm{o}}$ & $389.348 \pm 2.1 \mathrm{e}-5$ & $61.1286 \pm 6.6 \mathrm{e}-4$ \\
$\mathrm{~K}_{\mathrm{e}}$ & $0.999 \pm 0.14$ & $0.994 \pm 0.02$ \\
$\Delta \mathrm{G}_{\mathrm{ads}}$ & $2436.48 \pm 0.12$ & $5301.48 \pm 0.01$ \\
$\Delta \mathrm{G}_{\text {des }}$ & $22994.9 \pm 0.27$ & $24181.6 \pm 0.1$ \\
\hline
\end{tabular}

The confidence intervals of the estimated parameters are acceptable indicating a robust and predictive model. Using further experimental data the confidence intervals could be improved further.

The process and other kinetic parameters are presented in the Table 3 and Table 4.

Table 3. Process parameters and physical properties.

\begin{tabular}{llllll}
\hline$T_{0}\left[{ }^{\circ} \mathrm{C}\right]$ & $T_{\text {end }}\left[{ }^{\circ} \mathrm{C}\right]$ & Time $[\mathrm{sec}]$ & $\rho_{c}\left[\mathrm{~kg} / \mathrm{m}^{3}\right]$ & $m_{\mathrm{H}_{2} \mathrm{O}}[\mathrm{g}]$ & $m_{K D P}[\mathrm{~g}]$ \\
\hline 45 & 20 & 10800 & 2338 & 400 & 150 \\
\hline
\end{tabular}

Table 4 Kinetic and other parameters which are used in the model.

\begin{tabular}{lllllllll}
\hline $\mathrm{k}_{\mathrm{g} 1}$ & $\mathrm{~g}_{1}$ & $\mathrm{~kg}_{\mathrm{g} 2}$ & $\mathrm{~g}_{2}$ & $\mathrm{R}$ & $\mathrm{M}_{\mathrm{KDP}}$ & $\mathrm{M}_{\mathrm{H} 2 \mathrm{O}}$ & $\mathrm{M}_{\text {CGM1 }}$ & $\mathrm{M}_{\text {CGM2 }}$ \\
\hline 12.21 & 1.478 & 100.75 & 1.741 & 8.314 & 136.1 & 18.00 & 26.98 & 97.98 \\
\hline
\end{tabular}

The mean AR trends from simulation and experiments for the three experiments used in the parameter estimation are shown on Fig 5a. The experimental data during the initial part of the process were not used in the identification to avoid the non-reliable measurements due to the small number of captured particles after the nucleation. The AR measurement is relatively noisy 
due to the relatively lower number of captured particles and changing orientation of the crystals; however the simulated trends are in very good correlation with the experimental data.

Experiments Exp4 (with different amount of CGM1) and Exp5 (with a mixture of CGM1 and CGM2) were used for validation of the estimated kinetic parameters. Fig. 5b indicates very good correlation between the experiments and simulation in both cases when the impurity has independent effect (Exp4, Exp5) as well as when they act simultaneously (Exp6-9) suggesting that the MIAM proposed with the assumptions applied for the KDP-Al ${ }^{3+}$-metaphosphate system are valid. Trends on Figure 5, corresponding to Exp5 show a case when particle number is critical for the detection and measurement of statistically relevant AR. If the number of particles detected is small this can lead to large perturbation in the trend. The increasing number of particles due to nucleation, lead to larger numbers detected and thus decreases the noise in the AR measurement towards the second half of the process. Figure 6 presents sample PVM images at the end of the process. These images illustrate the changes in the crystal shape in each experiment.

\section{Sensitivity study of the effect of impurities on crystal shape and purity}

The validated model is suitable to study the crystallization process in impure media by investigating the effect of the concentrations of the impurities (or mixtures of impurities) on the crystallization process and crystal properties such as mean size and shape. By using the validated model, the effect of impurity concentrations on the crystallization behavior and crystal properties can be investigated using numerical simulations. Fig. 7 represents the simulation based study of evolution of supersaturation and the concentrations of the impurities (growth modifiers) in the case of different amounts of (a) CGM1 or (b) CGM2 in the initial solution. The results indicate 
that the lowest supersaturation values are achieved in the case of crystallization from pure solution. The impurities have inhibition effect on the phase transformation and on the crystallization process via growth inhibition, thus the depletion of supersaturation is slower in the presence of impurities which means, impurity indirectly affects not only the aspect ratio but the kinetics of the competitive processes such as nucleation and growth. The concentration of the CGMs is presented in ppm CGM per total amount of solvent. The figure also shows the dynamics of impurity concentration changes in the solution as they are integrated in the crystal lattice. It can be seen the higher the initial impurity concentration the faster they integrate into the crystal lattice, leading to more impure product.
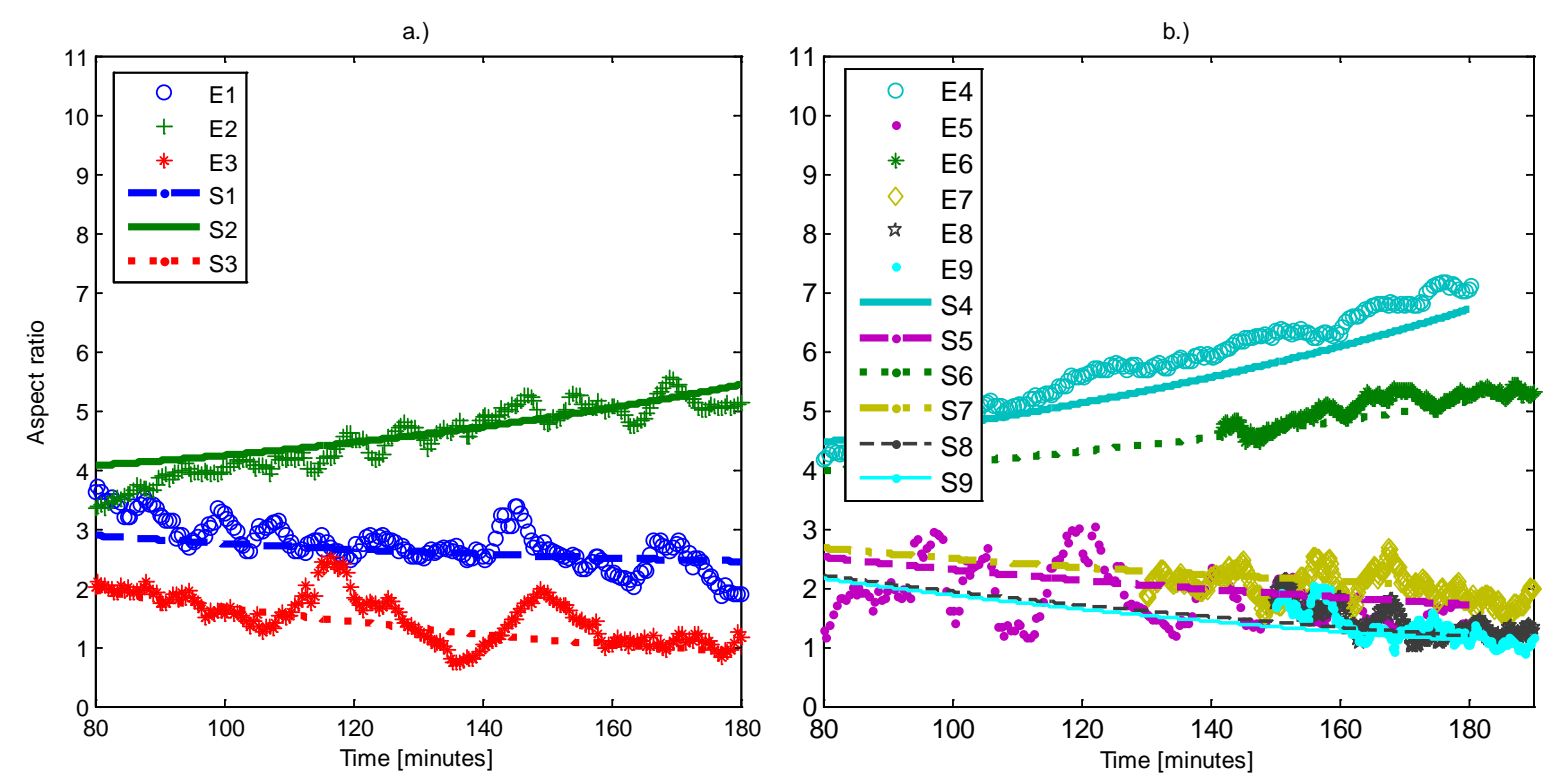

Figure 5. (a) Comparison between the experimental and simulated mean aspect ratio evolution for the data used in the identification of nucleation kinetic and parameters of impurity adsorption term (Table 2); (b) Comparison between the experimental and simulated mean aspect ratio evolution for the validation experiments. 


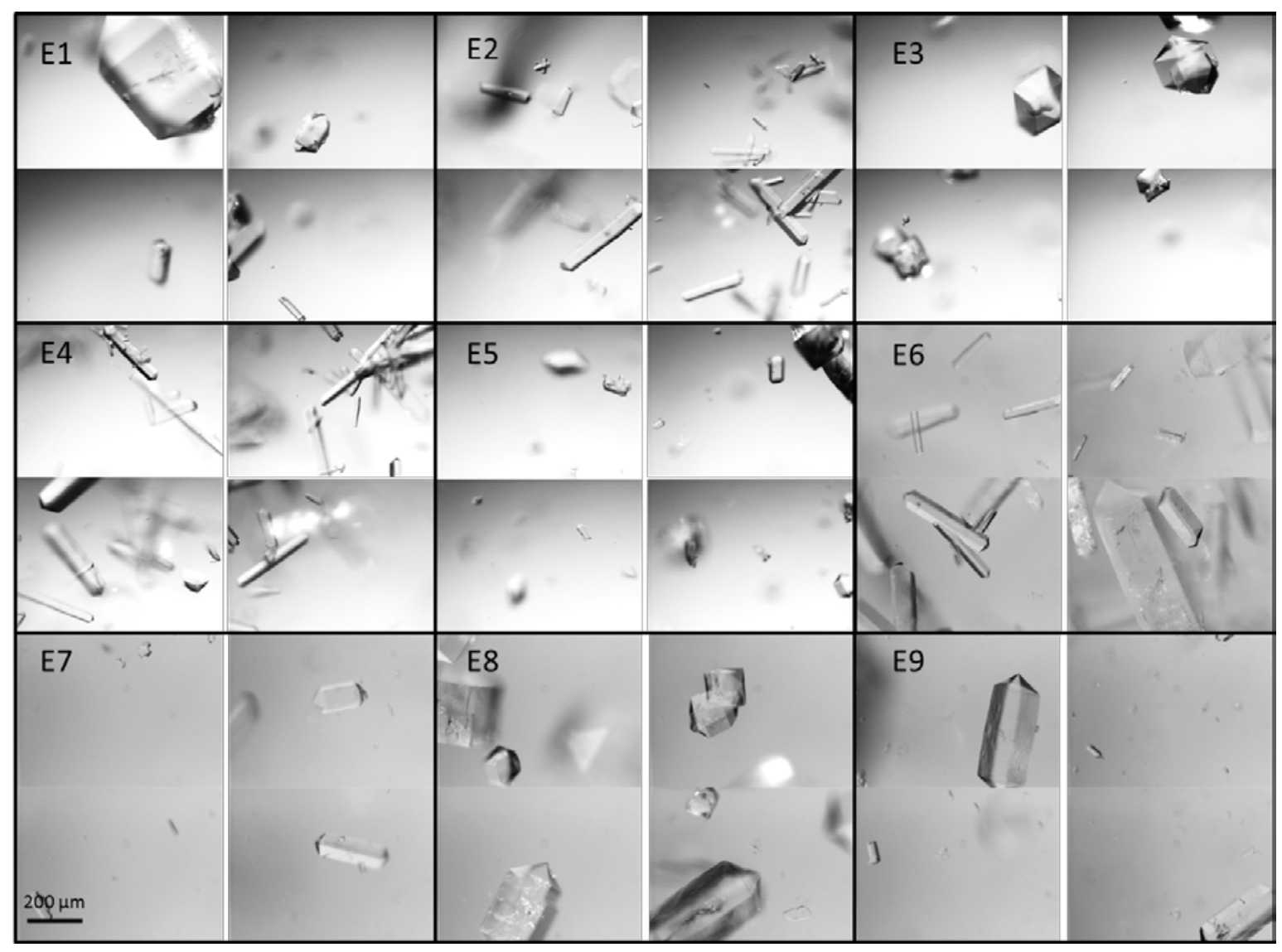

Figure 6. Sample PVM images at the end of each experiment.

Fig. 8 presents the changes in the kinetics of primary nucleation and growth rates during the crystallization process in the presence of different amounts of impurities. The CGM's inhibition effect on the growth of a specific characteristic crystal size can be observed. Since the inhibition slows down the supersaturation depletion, it influences the growth in the other direction as well as the primary nucleation indirectly via the changed supersaturation. Hence, the addition of the CGM1 into the system results in decreased growth rate of width $\left(\mathrm{x}_{2}\right)$ and increased growth rate of length (x1) while CGM2 causes higher growth rate of width and lower rate of length. The 
primary nucleation rates are increased in both cases since the supersaturation overall is kept higher in the system.
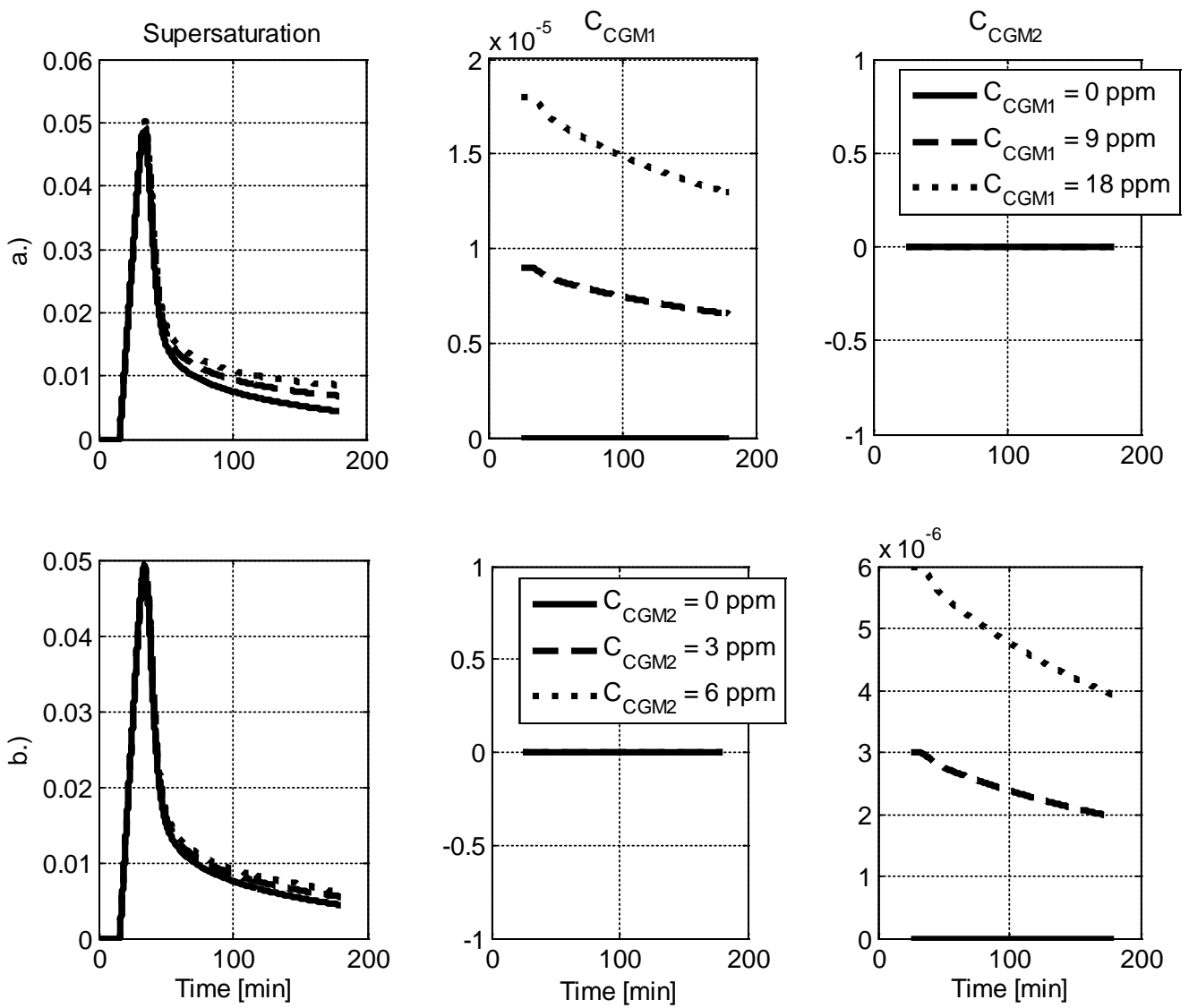

Figure 7. Evolution of supersaturation, liquid concentration of CGM1 and CGM2 in the presence of different amounts of (a) CGM1 and (b) CGM2 (concentration of other CGM is zero; concentration units are in ppm of CGM).

Fig. 9 presents the product properties at the end of the crystallization process, such as particle number, mean crystal length, and mean crystal width. It can be seen that not only the particle sizes but also the particle number of the product changes with the amount of CGMs. As expected, the product particle number is the smallest when there is no impurity in the system, to 
inhibit growth, as it could also be considered by investigation of the primary nucleation kinetics in Fig. 8.
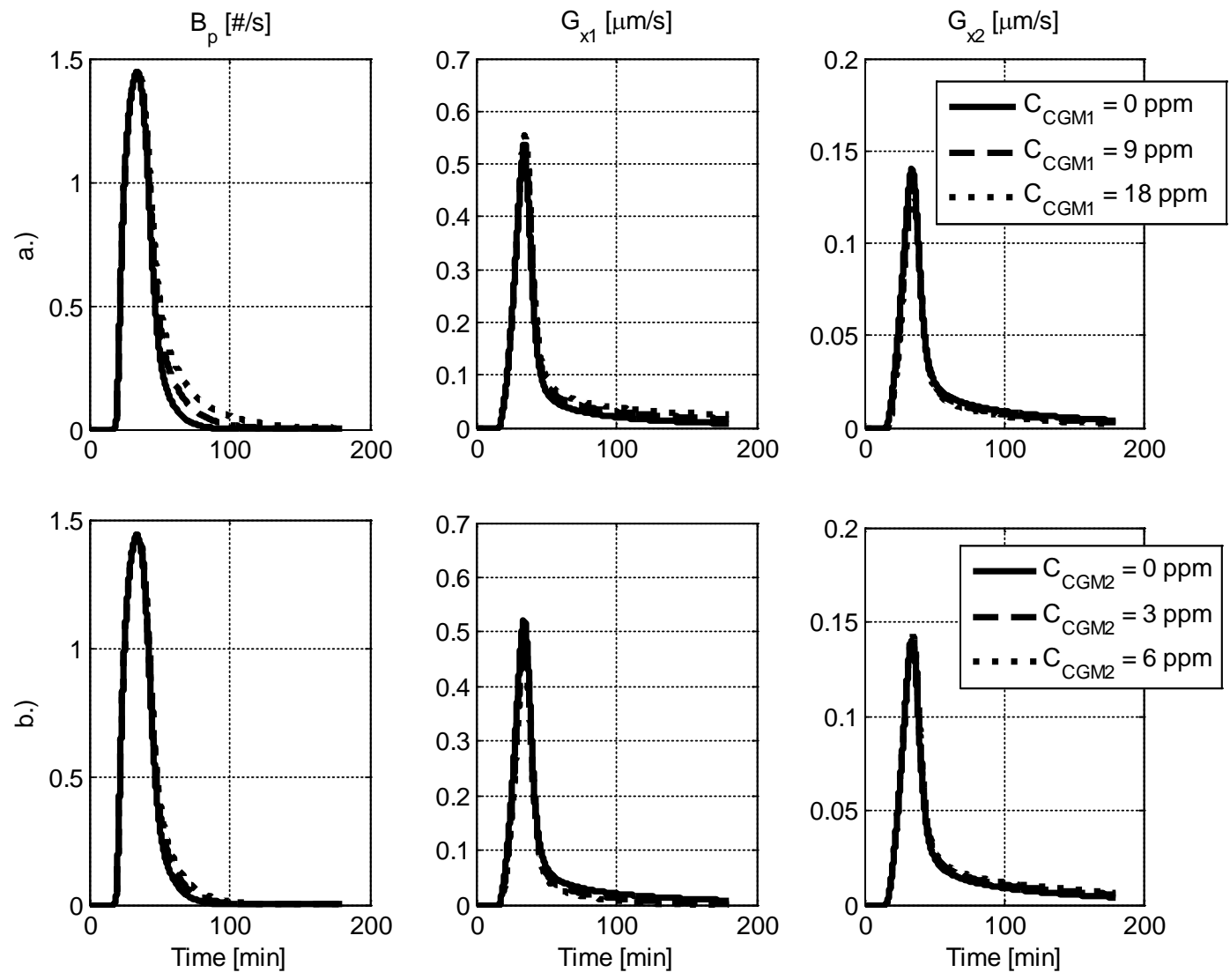

Figure 8. Evolution of the crystallization kinetics in the presence of different amounts of (a) CGM1 and (b) CGM2. 
a.) Particle number

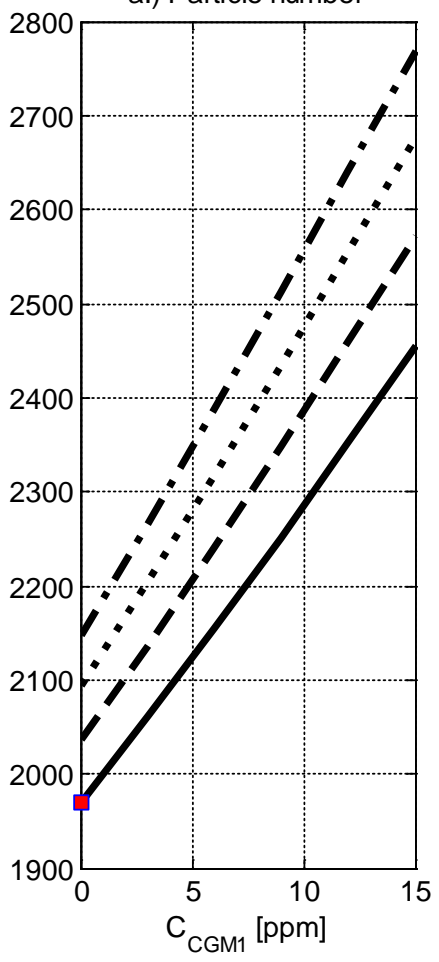

b.) $x_{1}[\mu \mathrm{m}]$

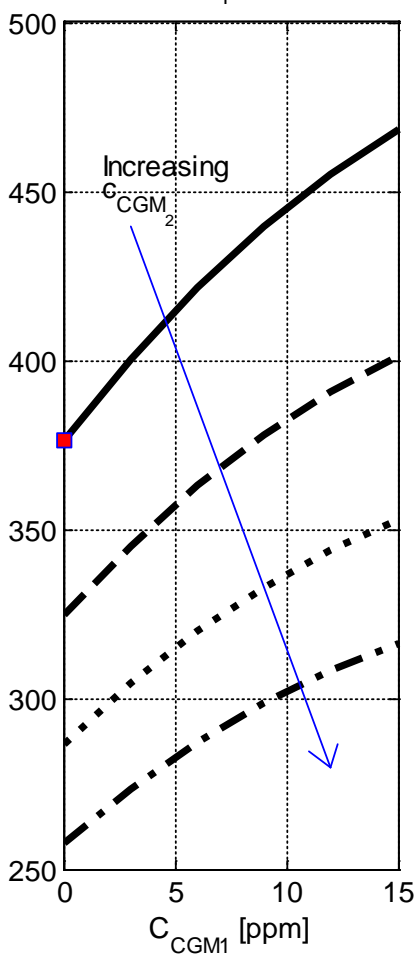

b.) $x_{2}[\mu \mathrm{m}]$

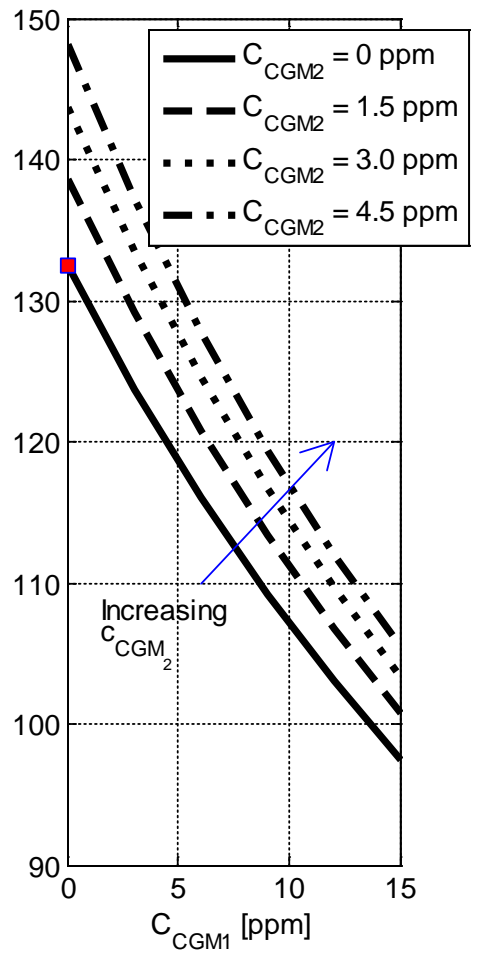

Figure 9. Effect of the impurity concentration (CGM1 and CGM2) on (a) particle number (\# m3); (b) mean crystal length $(\mu \mathrm{m})$; and (c) mean crystal width $(\mu \mathrm{m})$ of the crystal product at the end of the batch. The dots in the figure correspond to the product with no impurities.

Fig. 9a also shows the mixtures of the CGMs, that inhibit growth in both directions, result in increased number of particles. Furthermore, Fig. 9b and Fig. 9b represent the effect of the impurities on the mean crystal length and width at the end of the processes. The results show that since CGM1 is decreases the growth of the characteristic length $\mathrm{x}_{2}$ (width), increasing the concentration of CGM1 in the initial mixture leads to larger $\mathrm{x}_{1}$, and smaller $\mathrm{x}_{2}$. Contrary, increasing the concentration of the other impurity (CGM2) decreases $\mathrm{x}_{1}$, and increases $\mathrm{x}_{2}$. The resulting increase in a characteristic size of the crystals in the presence of a particular impurity is 
also due to the increased supersaturation in the system when the growth is partially inhibited for the other characteristic dimension.

Fig. 10 indicates how the amount of crystals produced and purity of crystal product changes with the impurity concentration in the initial solution. Fig10a shows the concentration of the solid KDP crystal in unit of solvent, obtained from the mass balance:

$$
c_{\text {solid }}(t)=c_{\text {initil }}-c(t)
$$

It can be seen that the impurity addition will influence not only the yield of the process. The red square represents the achievable maximum solid concentration of product, corresponding to the case of pure solution. Fig. 10b and Fig. 10c indicates the influence of the impurity concentrations of CGM1 and CGM2 on the purity of solid crystals with respect to each impurity, while Fig.10d represents the total impurity concentration in the solid phase at the end of the processes when different mixtures of CGMs were added. It is shown that the impurity is changing according to changes of both CGMs. 
a.)

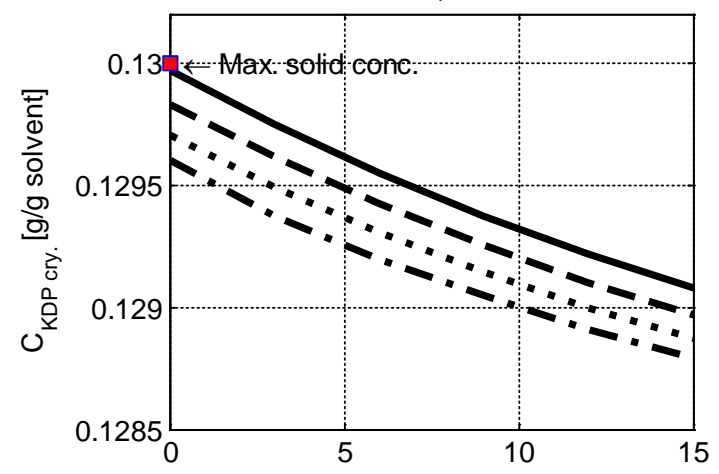

c.)

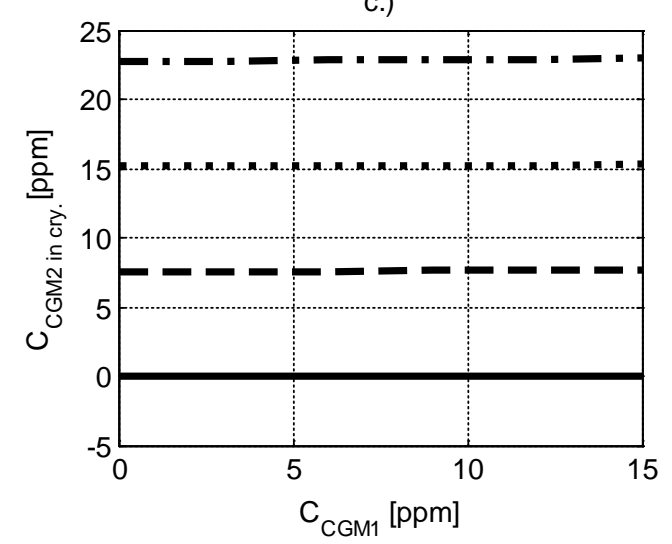

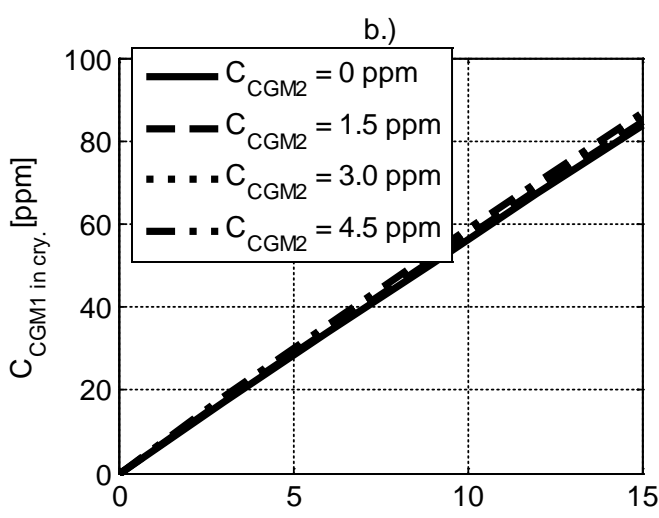

d.)

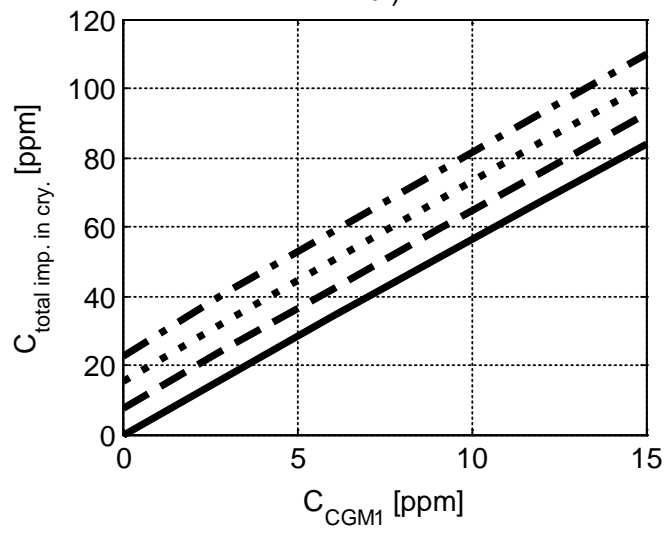

Figure 10. Influence of the concentration of two impurities in the initial solution on a) crystal concentration at the end of the process and purity of product crystals with respect to b) CGM1 c) CGM2 and d) total impurity at the end of the process. The impurity concentrations for b), c) and d) are presented in ppm based on unit solid crystals. The square on a) represents the maximum solid concentration corresponding to clear solution.

This work illustrates how trace amounts of impurity can have significant effect on the crystal product property such as size and shape. The concept is general as long as the suitable crystallization additives are identified that have the opposite effect on crystal shape as the impurities. Suitable additives can be found considering the different mechanisms of the 
adsorption and the potential chemical interactions at the surface of the crystal due to the molecular arrangements of the molecules within the crystal lattice, or based on general hydrophilic or hydrophobic nature of the crystal faces, which can be determined experimentally. While generally introducing additives in the crystallization system was not a preferred approach in the pharmaceutical industries, using approved hydrophilic/hydrophobic excipients and very low concentration of additives is gaining increasing applicability and interest. As in the case of the current study, often total impurity levels of the product remains at the ppm range, which is acceptable in most cases.

\section{Conclusions}

Physical experiments of batch KDP crystallization from aqueous solution, in the presence of mixtures of crystal growth modifiers were carried out in order to investigate the impurity effect on the growth and the morphology changes of the crystal. In situ, real time measurement of shape distribution by using Particle Vision and Measurement was used and the image sequences were analysed simultaneously in real time based on blob analysis technique. This automated optical monitoring system provided reliable data of shape distribution and mean aspect ratio. A multi-dimensional morphological population balance model was developed that included primary nucleation and growth of two characteristic crystal sizes in order to describe the shape of KDP crystals. A novel multi-impurity adsorption model (MIAM) is proposed and used in describing crystal growth in impure media. The MIAM model can describe the different effects of multiple impurities or impurity mixtures with components having different effects on the growth of certain characteristic sizes of crystals, using a mechanism of multi-component and multi-site adsorption. The parameters of the primary nucleation and growth kinetics, including 
the effect of a mixture of two impurities, were estimated by using least square method and validated by physical experiments. The developed and validated simulator is suitable to make dynamic observations of the kinetics and the evolution of the crystal properties such as size, shape and purity, during the crystallization process in impure media making the proposed model an effective tool for process and product design as well as for process optimization or control.

\section{Acknowledgment}

Financial support provided by the European Research Council grant no. [280106-CrySys] is gratefully acknowledged.

\section{Notation}

$\begin{array}{lll}a & - & \text { Area of the crystal per unit }\left[\mathrm{m}^{2}\right] \\ B_{p} & - & \text { Primary nucleation }[\# / \mathrm{s}] \\ c & - & \text { Concentration of KDP crystals in the solution }[\mathrm{g} / \mathrm{g} \text { solvent }] \\ c_{C G M, j} & - & \text { Concentration of the } j^{\text {th }} \text { crystal growth modifier }[\mathrm{g} / \mathrm{g} \text { solvent }] \\ C_{\text {sat }} & - & \text { Saturation concentration of KDP crystals in solution }[\mathrm{g} / \mathrm{g} \text { solvent }] \\ E_{p} & - & \text { Kinetic energy of primary nucleation }[\mathrm{kJ} / \mathrm{mol}] \\ \Delta G_{a d s, i, j, k} & - & \text { Adsorption energy }[\mathrm{kJ} / \mathrm{mol}] \\ \Delta G_{d e s, i, j, k} & - & \text { Desorption energy }[\mathrm{kJ} / \mathrm{mol}] \\ g_{i} & - & \text { Exponent of growth kinetic equitation of the } i^{\text {th }} \text { characteristic facet [-] } \\ G_{i} & - & \text { Crystal growth rate of the } i^{\text {th }} \text { characteristic facet }[\mu \mathrm{m} / \mathrm{s}]\end{array}$


$G_{\min , i} \quad$ - $\quad$ Specific growth rate when distribution does not occur $[\mu \mathrm{m} / \mathrm{s}]$

$k_{B} \quad-\quad$ Boltzmann factor $\left[\mathrm{m}^{2} \mathrm{~kg} \mathrm{~s}^{-2} \mathrm{~K}^{-1}\right]$

$K_{d, i, j} \quad$ - $\quad$ Distribution coefficient [-] (Eq14)

$k_{a d s, 0, i, j, k} \quad$ - $\quad$ Adsorption rate constant of the $j^{\text {th }}$ crystal growth modifier on the $k^{\text {th }}$ type site at $i^{\text {th }}$ characteristic crystal facet [-] (Eq5)

$k_{a d s, 0, i, j, k} \quad$ - $\quad$ Desorption rate constant of the $j^{\text {th }}$ crystal growth modifier on the $k^{\text {th }}$ type site at $i^{\text {th }}$ characteristic crystal facet [-] (Eq5)

$k_{e} \quad \quad-\quad \quad$ Kinetic constant of Primary nucleation [-]

$K_{e, j} \quad$ - $\quad$ Thermodynamic distribution coefficient [-]

$k_{g i} \quad-\quad$ Growth kinetic constant $[\mu \mathrm{m} / \mathrm{s}]$

$K_{i, j, k} \quad$ - $\quad$ Langmuir constant of $j^{\text {th }}$ CGM on the $k^{\text {th }}$ active site on $i^{\text {th }}$ characteristic facet (Eq7)

$k_{m, i, j} \quad$ - $\quad$ Mass transfer coefficient with crystal growth $[\mathrm{m} / \mathrm{s}]$

$k_{m 0} \quad-\quad$ Mass transfer coefficient without crystal growth $[\mathrm{m} / \mathrm{s}]$

$k_{p, 0} \quad-\quad$ Coefficient of primary nucleation $\left[\mathrm{m}^{-3} \mathrm{~s}^{-1}\right]$

$L_{i, k} \quad$ - $\quad$ Average distance between $k^{\text {th }}$ type of sites [ $\left.m\right]$

$M_{C G M, j} \quad$ - $\quad$ Molecular weight of CGM $[g]$

$M_{c} \quad$ - $\quad$ Molecular weight of KDP $[g]$

$n \quad-\quad$ Size and shape distribution $\left[\# / m^{2}\right]$

$p_{\text {imp }, i} \quad-\quad \quad \quad$ Impurity factor of the growth rate of $i^{\text {th }}$ characteristic facet (Eq2 and Eq7) 


\begin{tabular}{|c|c|c|}
\hline$R$ & - & Ideal gas constant $\left[\mathrm{Pa} \mathrm{m}^{3} \mathrm{~mol}^{-1} \mathrm{~K}^{-1}\right]$ \\
\hline$t$ & - & Time $[s]$ \\
\hline$T$ & - & Temperature $[K]$ \\
\hline$x_{i}$ & - & Size of $i^{\text {th }}$ characteristic crystal facet $[\mu m]$ \\
\hline$y_{l}$ & - & Numerically calculated aspect ratio at $k^{\text {th }}$ point in time [-] \\
\hline $9 / 1$ & - & Measured aspect ratio at $k^{\text {th }}$ point in time [-] \\
\hline \multicolumn{3}{|c|}{ Greek letters } \\
\hline$\alpha_{i, k}$ & - & Effectiveness factor of the adsorption on the $k^{\text {th }}$ site on $i^{\text {th }}$ characteristic \\
\hline \multicolumn{3}{|c|}{ facet (Eq5) } \\
\hline$b_{i, k}$ & - & Constant of the effectiveness factor $[\mathrm{m} / \mathrm{K}]$ \\
\hline$g_{i}$ & - & Edge free energy on the $i^{t^{t h}}$ crystal face per unit length $[\mathrm{J} / \mathrm{m}]$ \\
\hline$n$ & - & Size and shape distribution $\left[\# m^{-2} s^{-1}\right]$ \\
\hline$\eta_{j}$ & - & Time spent by a particle in the presence of impurities $[s]$ \\
\hline$\mu_{m, r}$ & - & $m, r$ order joint moment (Eq16) \\
\hline$\sigma$ & - & Relative supersaturation [-] \\
\hline$\rho_{c}$ & - & Density of the KDP crystals, $2.338\left[\mathrm{~kg} / \mathrm{m}^{3}\right]$ \\
\hline$\theta$ & - & Angle between $\{101\}$ and $\{100\}$ surfaces (Majumder and Nagy, 2013) \\
\hline$\Theta$ & - & Vector of estimated parameters \\
\hline$\theta_{e q, i, j, k}$ & - & Equilibrium coverage (Eq2) \\
\hline$\chi_{c, j}$ & - & Mole fraction of the CGM in the crystal phase (Eq15) \\
\hline$\tau_{i, j, k}$ & - & Adsorption time constant $[s]$ \\
\hline
\end{tabular}




\section{References}

1. Lovette, M.A.; Doherty, M.F. Predictive Modeling of Supersaturation-Dependent Crystal Shapes. Cryst. Growth Des. 2012, 12, 656-669.

2. Nagy, Z.K. Model Based robust control approach for batch crystallization product design. Comput. Chem. Eng. 2009, 33, 1685-1691.

3. Nagy, Z.K.; Braatz, R.D. Advances and New Directions in Crystallization Control. Annu. Rev. Chem. Biomol. Eng. 2012, 3, 55-75.

4. Larsen, P.A.; Rawlings, J.B.; Ferrier, N.J. An algorithm for analyzing noisy, in situ images of high-aspect-ratio crystals to monitor particle size distribution. Chem. Eng. Sci. 2006, 61, 5236-5248.

5. Ho, R.; Naderi, M.; Heng, J.Y.Y.; Williams, D.R.; Thielmann, F.; Buaza, P.; Keith, A.R.; Thiele, G.; Burnett, D.J. Effect of milling on the particle shape and surface energy heterogeneity of needle-shape crystals. Pharm. Res. 2012, 29, 2806-2816.

6. Yang, G.; Kubota, N.; Sha, Z.; Louhi-Kultanen, M.; Wang, J. Crystal shape control by manipulating supersaturation in batch cooling crystallization. Cryst. Growth Des. 2006, 6, 2799-2803.

7. Bajcinca, N.; Oliveira, V.; Borchert, C.; Raisch, J.; Schundmacher, K. Optimal control solutions for crystal shape manipulation. Comp. Aided Chem. Eng. 2010, 28, 751-756.

8. Lovette, M.A.; Browning, A.R.; Griffin, D.W.; Sizemore, J.P.; Snyder, R.C.; Doherty, M.F. Crystal shape engineering. Ind. Eng. Chem. Res. 2008, 47, 9812-9833.

9. Acevedo, D.; Nagy, Z.K. Systematic classification of unseeded batch crystallization systems for achievable shape and size analysis. J. Cryst. Growth 2014, 394, 97-105.

10. Biscans, B.; Chemini, R.; Guiraud, P.; Laguerie, C. Design of an attrition experiment to simulate the effect of crystal-wall or crystal-stirrer impacts occur in crystallization. Powder Technol. 1996, 86, 155-161.

11. Sato, K.; Nagai, H.; Hasegawa, K.; Tomori, K.; Kramer, H.J.M.; Jansens, P.J. Twodimensional population balance model with breakage of high aspect ratio crystals for batch crystallization. Chem. Eng. Sci. 2008, 63, 3271-3278.

12. Borsos, A.; Lakatos, B.G. Investigation and simulation of crystallization of high aspect ratio crystals with fragmentation. Chem. Eng. Res. Des. 2013, 92, 1133-1141.

13. Prasad, K.V.R.; Ristic, R.I.; Sheen, D.B.; Sherwood, J.N.; Crystallization of paracetamol from solution in the presence and absence of impurity. Int. J. Pharm. 2001, 215, 29-44.

14. Plomp, M.; McPherson, A.; Malkin, A.J. Repair of impurity-poisoned protein crystal surfaces. PROTEINS 2003, 50, 486-495.

15. Shan'gin, E.A. Development of the crystallization method for removing lead impurity from secondary zinc. Russ. J. Non-Ferr. Met. 2013, 54, 51-55. 
16. Fu, Y-J.; Gao, Z-S.; Liu, J-M.; Li, Y-P.; Zeng, H.; Jiang, M-H. The effect of anionic impurities on the growth habit and optical properties of KDP. J. Cryst. Growth 1999, 198-199, 682-686.

17. Variankaval, N.; Cote, A.S.; Doherty, M.F. From form to function: Crystallization of active pharmaceutical ingredients. AIChE J. 2008, 54, 1682-1688.

18. Nagy, Z.K.; Fevotte, G.; Kramer, H.; Simon, L.L. Recent advantages in the monitoring, modeling and control of crystallization systems. Chem. Eng. Res. Des. 2013, 91, 19031922.

19. Myerson, A.S. Handbook of industrial Crystallization, $2^{\text {nd }}$ edition, ButterworthHeinmann: Boston, 2001.

20. Rosenberg, F.; Riveros, H.G. Segregation in alkali halide crystallization from aqueous solutions. J. Chem. Phys. 1974, 60(2), 668-674.

21. Cabrera, N.; Vermilyea, D.A. The growth of crystal from solution. In: Dormeus, R.H.; Roberts, B.W.; Turnbull, D.: Growth and perfection of crystals, Chapman and Hall: London, 1958.

22. Davey, R.J. The effect of impurity adsorption ion the kinetics of crystal growth from solution. J. Cryst. Growth 1976, 34, 109-119.

23. Sizemore, J.P.; Doherty, M.F. A new model for the effect of molecular imposters on the shape of faceted molecular crystals. Cryst. Growth Des. 2009, 9, 2637-2645.

24. Kubota, N.; Mullin, J.W. A kinetic model for crystal growth from aqueous solution in the presence of impurity. J. Cryst. Growth 1995, 152(3), 203-208.

25. Kubota, N. Effect of impurities on the crystal growth kinetics of crystals. Cryst. Res. Technol. 2001, 36, 749-769.

26. Kubota, N.; Sasaki, S.; Doki, N.; Minamikawa, N.; Yokota, M. Absorption of an Al(III) impurity onto the (100) face of a growing KDP crystal in supersaturated solution. Cryst. Growth Des. 2004, 4, 533-537.

27. Majumder, A.; Nagy, Z.K. Prediction and control of crystal shape distribution in the presence of crystal growth modifiers. Chemical Engineering Science 2013, 101, 598-602.

28. Ruthven, D.M. Principles of adsorption and adsorption processes. John Wiley and Sons: Canada, 1985.

29. Rabe, M.; Verdes, D.; Seeger, S. Understanding protein adsorption phenomena at solid surfaces. Adv. Colloid Interface Sci. 2011, 162, 87-106.

30. Lim, B-G.; Ching, C-B.; Tan, R.B.H. Determination of competitive adsorption isotherms of enantiomers on dual-site adsorbent. Sep. Technol. 1995, 5, 213-228.

31. Gu, T.; Tsai, G-J.; Tsao, T. Multicomponent adsorption and chromatography with uneven saturation capacities. AIChE J. 1991, 37, 1333-1340.

32. Borsos, A.; Majumder, A.; Nagy, Z.K. Simulation, design and control of crystal shape by using tailored mixtures of crystal growth modifiers. Comp. Aided Chem. Eng. 2014, 33, 781-786. 
33. Patience, D.B.; Rawlings, J.B. Particle-shape monitoring and control in crystallization processes. AIChE J. 2001, 47, 2125-2130.

34. Wang, X.Z.; De Anda, J.C.; Roberts, K.J.; Li, R.F.; Thomson, G.B.; White, G. Advances in on-line monitoring and control of the morphological and polymorphic forms of organic crystals grown form solution. KONA Powder Part. J. 2005, 23, 69-85.

35. Simon, L.L.; Nagy, Z.K.; Hungerbuhler, K. Comparison of external bulk video imaging with focused beam reflectance measurement and ultra-violet visible spectroscope for metastable zone identification in food and pharmaceutical crystallization processes. Chem. Eng. Sci. 2009, 64, 3344-3351.

36. Simon, L.L.; Oucherif, K.A.; Nagy, Z.K.; Hungerbuhler, K. Histogram matching, hypothesis testing and statistical control-chart-assisted nucleation detection using bulk video imaging for optimal switching between nucleation and seed conditioning steps. Ind. Eng. Chem. Res. 2010, 49, 9932-9944.

37. Presles, B.; Debayle, J.; Rivoire, A.; Pinoli, J-C.; Fevotte, G. In situ particle size measurement during crystallization processes using image analysis. Nicholas R. XII Congres de la Societe Francaise de Genie des Pour relever les defies industriels du XXI siècle A la croisee des Sciences et des Cultures. Marseille, France, 2009; pp. 98-104.

38. Wang, X.Z.; De Anda, J.C.; Roberts, K.J. Real-time measurement of the growth rates of individual crystal facets using imaging and image analysis. A feasible study on needleshaped crystals of L-glutamis acid. Chem. Eng. Res. Des. 2007, 85, 921-927.

39. De Anda, J.C.; Wang, X.Z.; Roberts, K.J.; Multi-scale segmentation image analysis for the in-process monitoring of particle shape with batch crystallizers. Chem. Eng. Sci. 2005, 60, 1053-1065.

40. De anda, J.C.; Wang, X.Z.; Roberts, K.J.; Jennings, K.H.; Wilkinson, M.J.; Watson, D.; Roberts, D. Real-time product morphology monitoring in crystallization using imaging technique AIChE J. 2005, 51, 1406-1414.

41. Ma, C.Y.; Wang, X.Z. Model identification of crystal facet growth kinetics in morphological population balance modeling of L-glutamic acid crystallization and experimental validation. Chem. Eng. Sci. 2012, 70, 22-30.

42. Ma, C.Y.; Wang, X.Z. Closed-loop control of crystal shape in cooling crystallization of L-glutamic acid. Journal of Process Control 2012, 22, 72-81.

43. Randolph, A.D.; Larson, M.A. Transient and steady state size distributions in continuous mixed suspension crystallizer AIChE J. 1965, 8, 639-645.

44. Ramkrishna, D. Population balances: Theory and Applications to particulate System in Engineering. Academic Press: San Diego, 2000.

45. Puel, F.; Fevotte, G.; Klein, J.P. Simulation and analysis of industrial crystallization processes through multidimensional population balance equations. Part 1: a resolution algorithm based on the method of classes. Chem. Eng. Sci. 2003, 58, 3715-3727. 
46. Puel, F.; Fevotte, G.; Klein, J.P. Simulation and analysis of industrial crystallization processes through multidimensional population balance equations. Part 2: a study of semi-batch crystallization. Chem. Eng. Sci. 2003, 58, 3729-3740.

47. Gunawan, R.; Fusman, I.; Braatz, R.D. High resolution algorithm for multidimensional population balance equations. Particle Tech. Fluidization 2004, 50, 2738-2749.

48. Zhang, Y.; Doherty, M.F. Simultaneous prediction of crystal shape and size for solution crystallization. AIChE J. 2004, 50, 2101-2112.

49. Ma, C.Y.; Wang, X.Z.; Roberts, K.J. Morphological Population balance for modeling crystal growth in face directions. AIChE J. 2007, 54, 209-222.

50. Borsos, A.; Lakatos, B.G. Influence of breakage on crystal size distribution in a continuous cooling crystallizer. Periodica Polytechnica 2012, 56, 65-69.

51. Borchert, C.; Sundmacher, K. Morphology evolution of crystal populations: Modeling and observation analysis. Chem. Eng. Sci. 2012, 70, 87-98.

52. Majumder, A.; Kariwala, V.; Ansumali, S.; Rajendran, A. Lattice Boltzmann method for solving multi-dimensional population balance models in crystallization. Chem. Eng. Sci. 2012, 70, 121-134.

53. Kwon, J.S-I.; Nayhouse, M.; Christofides, P.D.; Orkoulas, G. Modeling and control of protein crystal shape and size in batch crystallization. AIChE J. 2013, 59, 2317- 2327.

54. Ding, J.; Lu, Y.; Wang, S.; Mu, X.; Gu, Q.; Wang, Z.; Sun, Y.; Liang, X.; Xu, X.; Sun, $\mathrm{X}$; Liu, W.; Zhu, S. Influence of $\mathrm{SiO}_{3}{ }^{2-}$ impurity on growth of potassium dihydrogone phosphate crystal. Cryst. Res. Des. 2010, 45, 800-804.

55. Rak, M.; Eremin, N.N.; Eremina, T.A.; Kuznetsov, V.A.; Okherimenko, T.M.; Furmanova, N.G.; Efremova, EP. On the mechanism of impurity influence on growth kinetics and surface morphology of KDP crystals-I: Defect centers formed by bivalent and trivalent impurity ions incorporated in KDP structure-theoretical study. J. Cryst. Growth 2005, 273, 577-585.

56. Eremina, T.A.; Kuznetsov, V.A.; Eremin, N.N.; Okhrimenko, T.M.; Furmanova, N.G.; Efremova, E.P.; Rak, M. On the mechanism of impurity influence on growth kinetics and surface morphology of KDP crystals-II: experimental study of influence of bivalent and trivalent impurity ions on growth kinetics and surface morphology of KDP crystals. $J$. Cryst. Growth 2005, 273, 586-593.

57. Fevotte, F.; Fevotte, G. A method of characteristics for solving population balance equations (PBE) describing the adsorption of impurities during crystallization processes. Chem. Eng. Sci. 2010, 65, 3191-3198.

58. Bharati, M.H.; Liu, J.J.; MacGregor, J.F. Image texture analysis: methods and comparisons. Chemometr. Intell. Lab. 2004, 72, 57-71.

59. Zhang, B.; Abbas, A.; Romagnoli, J.A. Monitoring crystal growth based on image texture analysis using wavelet transformation. In: Proceedings of $8^{\text {th }}$ IFAC Symposium on Advanced Control of Chemical Processes, Furama Riverfront, Singapore, 2012. 
60. Simon, L.L.; Merz, T.; Dubuis, S.; Lieb, A.; Hungerbuhler, K. In-situ monitoring of pharmaceutical and specialty chemicals crystallization process using endoscopystroboscopy and multivariate image analysis. Chm. Eng. Res. Des. 2012, 90, 1847-1855.

61. Schorsch, S.; Vetter, T.; Mazzotti, M. Measuring multidimensional particle size distribution using crystallization. Chem. Eng. Sci. 2012, 77, 130-142.

62. Zhou, Y.; Doan, X-T.; Srinivasan, R. On-line monitoring of particle shape and size distribution in crystallization process through image analysis. In: European Symposium on Computer Aided Process Engineering (ESCAPE-17), Elsevier, Amsterdam, 2007.

63. Zhou, Y.; Lakshminarayanan, S.; Srinivasan, R. Optimization of image processing parameters for large set of in-process video microscopy images acquired from batch crystallization processes: Integration of uniform design and simplex search. Chemometr. Intell. Lab. 2011, 107, 290-3020.

64. Larson, P.A.; Rawlings, J.B. Assessing the reliable of particle number density measurements obtained by image analysis. Part. Part. Syst. Char. 2008, 25, 420-433.

65. Schorsch, S.; Ochsenbein, D.R.; Vetter, T.; Morari, M.; Mazzotti, M. High accuracy online measurement of multidimensional particle size distribution during crystallization. Chem. Eng. Sci. 2014, 105, 155-168.

66. Sangwal, K. Effects of impurities on crystal growth process. Prog. Cryst. Growth Charact. Mater. 1996, 32, 3-43.

67. Sitprasert, C.; Zhu, Z.H.; Wang, F.Y.; Rudolph, V. Multi-component adsorption in the heterogeneous carbonaceous porous media through the integration of small-scale, homogeneous models. Chem. Eng. Sci. 2013, 95, 267-282.

68. Ferreira, A.; Rocha, F.A.; Damas, A.M.; Martins, P.M. On the growth rate hysteresis and catastrophic crystal growth. J. Cryst. Growth 2013, 368, 47-55.

69. Lenka, M.; Sarkar, D. Determination of metastable zone width, induction period and primary nucleation kinetics for cooling crystallization of L-asparaginenohydrate. J. Cryst. Growth 2014, 408, 85-90.

70. Maeda, K.; Tabuchi, R.; Asakuma, Y.; Fukui, K. Distribution of metallic ions in single KDP crystal grown from aqueous solution. Cryst. Res. Technol. 2006, 41, 955-960.

71. Hulbert, H.M.; Katz, S. Some problem in particle technology: A statistical mechanical formulation. Chem. Eng. Sci. 1964, 19, 555-574.

72. Ma, D.L.; Tafti, D.K.; Braatz, R.B. Optimal control and simulation of multidimensional crystallization processes. Comp. Chem. Eng. 2002, 26, 1103-1116.

73. Briesen, H. Simulation of crystal size and shape by means of a reduced two-dimensional population balance model. Chem. Eng. Sci. 2006, 61, 104-12.

74. Yang, Y.; Nagy, Z.K. Model-based systematic design approach for combined cooling and antisolvent crystallization (CCAC) systems. Cryst. Growth Des. 2014, 14, 687-698.

75. Salter, E.A., Wierzbicki, A., Land, T. Ab initio study of Al(III) adsorption on stepped 100 surfaces of KDP crystals. Struct. Chem. 2005, 16, 111-116. 
76. Dam, B., Polman, E., van Enckevort W.J.P. In situ observation of surface phenomena on $\{100\}$ KDP related to growth kinetics and impurity action. In: Jancic, S.D., de Jong, E.J. Industrial Crystallization 84 ${ }^{\text {th }}$ ed. Elsevier, Amsterdam, 1984, 97-102.

77. Rashkovich, L.N., Kronsky, N.V. Influence of Fe3+ and Al3+ ions on the kinetics of steps on the $\left\{\begin{array}{lll}1 & 0 & 0\end{array}\right\}$ faces of KDP. J. Cryst. Growth 1997, 182, 434-441.

78. Van Enckevort, W.J.P., Jansen-Van Rosmalen, R., ven der Linden, W.H. Evidence for spiral growth on the pyramidal faces of KDP and ADP single crystals. J. Cryst. Growth 1980, 49, 502-514.

79. Simon, L.L., Pataki, H., Marosi, Gy., Meemken, F., Hungerbuhler, K., Baiker, A., Tummala, S., Glennon, B., Kuentz, M., Steele, G., Kramer, H.J.M., Rydzak, J.W., Chen, Z., Morris, J., Kjell, F., Singh, R., Gani, R., Garnaey, K.V., Louhi-Kultanen, M., O’Reilly, J., Sandler, N., Antikainen, O., Yliruusi, J., Frohberg, P., Ulrich, J., Braatz, R.D., Leyssens, T., von Stosch, M., Oliviera, R., Tan, R.B.H., Wu, H., Khan, M., O’Grady, D., Pandey, A., Westra, R., Delle-Case, E., Pepe, D., Angelosante, D., Maret, Y., Steiger, O., Lenner, M., Abbou-Oucherif, K., Nagy, Z.K., Lister, J.D., Krishna Kamaraju, V., Chiu, M-S. Assessment of recent process analytical technology (PAT) trends: a multiauthor review. Org. Proc. Res. Dev. 2015, 19, 3-62.

80. Chung, S.H., Ma, D.L., Braatz, R.D. Optimal model-based experimental design in batch crystallization. Chem. Intelligent Lab. Sys. 2000, 50, 83-90.

81. Nagy, Z.K., Fujiwara, M., Woo, X.Y., Braatz, R.D. Determination of the kinetics parameters for the crystallization of Paracetamol from water using metastable zone width experiments. Ind. Eng. Chem. Res. 2008, 47, 12475-1252.

82. Yu, Z.Q., Chow, P.S., Tan, R.B.H. Seeding and constant-supersaturation control by ATR-FTIR in anti-solvent crystallization. Org. Proc. Res. Dev. 2006, 10, 717-722.

83. Nagy, Z.K., Aamir, E. Systematic design of supersaturation controlled crystallization processes for shaping the crystal size distribution using an analytical estimator. Chem. Eng. Sci. 2012, 84, 656-670.

84. Alexandru, H.V., Antohe, S. Prismatic faces of KDP crystal, kinetic and mechanism of growth from solutions. J. Cryst. Growth, 2003, 258, 149-157.

85. De Yoreo, J.J., Land, T.A., Dair, B. Growth Morphology of Vicinal Hillocks on the $\{101\}$ Face of KH2PO4: From Step-Flow to Layer-by-Layer Growth. Phys. Rev. Lett. 1994, 73, 838-841.

86. Fu, Y. J., Gao, Z. S., Liu, J. M., Li, Y. P., Zeng, H., \& Jiang, M. H. (1999). The effects of anionic impurities on the growth habit and optical properties of KDP. J. Cryst. Growth, 1999, 198, 682-686. 


\section{For Table of Contents Use Only}

Title: Multi-impurity adsorption model for modeling crystal purity and shape evolution during crystallization processes in impure media

Authors: Akos Borsos, Aniruddha Majumder, Zoltan K. Nagy

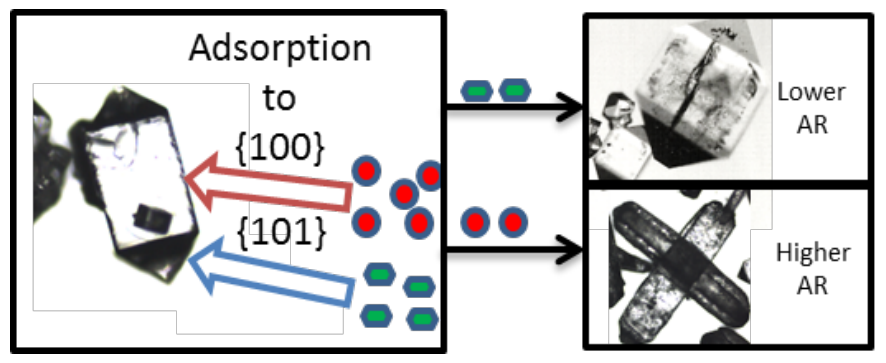

Synopsis: Multi-impurity adsorption based inhibitory effect of crystal surface growth from impure media and its impact on the crystal shape is investigated; multi-impurity adsorption model is developed. The strong correlation between the concentration of the impurities and the crystal aspect ratio (AR) is studied, modelled and discussed in the present work. 